\title{
Muscle metabolomics analysis reveals potential biomarkers of exercise-dependent improvement of the diaphragm function in chronic obstructive pulmonary disease
}

\author{
JIAN LI ${ }^{1}$, YUFAN LU ${ }^{1}$, NING LI ${ }^{1}$, PEIJUN LI $^{1}$, JIANQING SU$^{1}$, ZHENGRONG WANG $^{1}$, \\ TING WANG ${ }^{1}$, ZHAOYU YANG ${ }^{1}$, YAHUI YANG ${ }^{1}$, HAIXIA CHEN $^{2}$, LU XIAO $^{3}$, \\ HONGXIA DUAN $^{3}$, WEIBING WU ${ }^{1}$ and XIAODAN LIU $^{3,4}$
}

\author{
${ }^{1}$ Department of Sports Medicine, ${ }^{2}$ School of Physical Education and Sport Training, Shanghai University of Sport, \\ Shanghai $200438 ;{ }^{3}$ School of Rehabilitation Science, Shanghai University of Traditional Chinese Medicine; \\ ${ }^{4}$ Institute of Rehabilitation Medicine, Shanghai Academy of Traditional Chinese Medicine, Shanghai 201203, P.R. China
}

Received September 26, 2019; Accepted February 17, 2020

DOI: $10.3892 /$ ijmm.2020.4537

\begin{abstract}
Decreased diaphragm function is a crucial factor leading to reduced ventilatory efficiency and worsening of quality of life in chronic obstructive pulmonary disease (COPD). Exercise training has been demonstrated to effectively improve the function of the diaphragm. However, the mechanism of this process has not been identified. The emergence of metabolomics has allowed the exploration of new ideas. The present study aimed to analyze the potential biomarkers of exercise-dependent enhancement of diaphragm function in COPD using metabolomics. Sprague Dawley rats were divided into three groups: COPD + exercise group (CEG); COPD model group (CMG); and control group (CG). The first two groups were exposed to cigarette smoke for 16 weeks to establish a COPD model. Then, the rats in the CEG underwent aerobic exercise training for 9 weeks. Following confirmation that exercise effectively improved the diaphragm function, a gas chromatography tandem time-of-flight mass spectrometry analysis system was used to detect the differential metabolites and associated pathways in the diaphragm muscles of the different groups. Following exercise intervention, the pulmonary function and diaphragm contractility of the CEG rats were significantly improved compared with those of the CMG rats. A total of 36 different metabolites were identified in the
\end{abstract}

Correspondence to: Professor Weibing Wu, Department of Sports Medicine, Shanghai University of Sport, 399 Changhai Road, Yangpu, Shanghai 200438, P.R. China

E-mail:wwb75@126.com

Professor Xiaodan Liu, School of Rehabilitation Science, Shanghai University of Traditional Chinese Medicine, 1200 Cailun Road, Pudong, Shanghai 201203, P.R. China

E-mail: hzhp403@126.com

Key words: chronic obstructive pulmonary disease, diaphragm, exercise, metabolomics comparison between the CMG and the CG. Pathway enrichment analysis indicated that these different metabolites were involved in 17 pathways. A total of 29 different metabolites were identified in the comparison between the CMG and the CEG, which are involved in 14 pathways. Candidate biomarkers were selected, and the pathways analysis of these metabolites demonstrated that 2 types of metabolic pathways, the nicotinic acid and nicotinamide metabolism and arginine and proline metabolism pathways, were associated with exercise-induced pulmonary rehabilitation.

\section{Introduction}

Chronic obstructive pulmonary disease (COPD) is becoming a significant cause of mortality and disability worldwide due to the aging population, the increasing number of smokers and worsening air pollution (1). Among the numerous symptoms of COPD, the decline of the respiratory function is a crucial factor affecting the quality of life of patients (2), and the respiratory failure caused by respiratory muscle dysfunction is the most severe symptom of COPD, given that respiratory failure is closely related to the mortality rate of patients with COPD. The maximum inspiratory pressure, which is closely associated with the function of inspiratory muscle, also represents one of the independent factors affecting the survival rate of these patients (3). A previous study demonstrated that the respiratory muscle dysfunction observed in patients with COPD is caused by chronic increased mechanical load (4). The decline in respiratory muscle function has also been demonstrated to be induced by multiple mechanisms, such as chronic inflammatory infiltration (5) and oxidative stress (6), which severely decrease the ventilation capacity of patients with COPD. The diaphragm, as the most important source of mechanical power in respiratory movement, is significantly affected in this process and has also the primary subject of previous studies $(7,8)$. In patients with early COPD, the diaphragm may compensate for poor ventilation (9), although it becomes gradually damaged by the increasing ventilation load combined with systemic inflammation (10), oxidative 
stress (11) and other factors. The decline in diaphragm muscle strength and endurance in patients with COPD makes it impossible for these patients to generate enough pressure to obtain normal ventilation levels, which further worsens respiratory distress (12). Improving the diaphragm function of patients with COPD is of great significance in improving their respiratory status and quality of life.

As the understanding of the significance of diaphragm function in COPD improves, various interventions have been proposed to improve diaphragm function; however, only one intervention was demonstrated to be effective in reversing such abnormalities, exercise training (13). As an important means of lung rehabilitation, exercise training is considered the cornerstone of COPD management. A large number of clinical studies have demonstrated that the effects of exercise training on the muscle function of patients with COPD are not only observed in the skeletal muscles of limbs, but also in the respiratory muscles such as the diaphragm (14). Simultaneously, how exercise training induces the improvement of COPD muscle function has been demonstrated, such as the effect of long-term aerobic exercise on the improvement of skeletal muscle stamina, in which fatigue-prone IIB and IIX fibers are transformed into fatigue-resistant type I fibers, enhancing the mitochondrial content and activity, as well as the muscle sugar transport capacity (15). Different types of exercise training may activate independent signaling pathways (16), leading to different skeletal muscle adaptation. Concomitantly, as a complex stimulus on the body (17), exercise may have effects on diaphragm dysfunction in multiple ways. Unfortunately, the existing data are not sufficient to explain the specific mechanism of exercise-dependent enhancement of diaphragm function. Therefore, further exploration of the underlying molecular mechanisms of this improvement in diaphragm function in COPD may lead to the improvement of lung rehabilitation.

Rapid advances in technology have allowed the identification of candidate biomarkers associated with different clinical phenotypes. The emergence of genomics, transcriptomics, proteomics and metabolomics has provided new methods of exploring the pathogenesis and therapeutic targets of diseases (18). However, the low concordance between gene-level and protein-level analysis limits this top-down mechanism approach (19); in general, transcriptome data do not generally reflect the true metabolic level of tissues and organs, which is associated with multiple complex and undetermined factors that are involved in the generation of metabolites from genes. Therefore, analysis of gene-level data cannot fully reveal the specific changes associated with the physiological and biochemical statuses of a biosystem relative to phenotype. Fortunately, the emergence of metabolomics addressed this issue.

Normal physiological processes and external stimulation cause changes in the types and quantities of metabolites, which may be quantitatively and qualitatively analyzed by metabolomics (20). The physiological and biochemical phenotypes can be determined by identifying changes in metabolites, and these data can infer the mechanism of disease progression or potential therapeutic targets. Therefore, metabolomics has been widely used in disease diagnosis, medical research and development, nutritional food science and other fields (21).
Considering that exercise intervention is a complex form of stimulation, non-target processing in metabolomics could be used to screen a wide range of different metabolites prior and subsequent to exercise intervention. Based on existing data (22) and our previous study (23), underwater exercise was considered to be a more suitable exercise mode for patients with COPD compared with land activities. Previously, long-term cigarette smoke exposure (CSE) was considered to be a method to establish a COPD model with respiratory muscle dysfunction (24-26), and it caused systemic changes in rats, including oxidative stress (27) and systemic inflammation (28), and also induced a dysregulation of skeletal muscle protein synthesis and decomposition, resulting in COPD muscle dysfunction (29). In the present study, CSE was used to establish a COPD rat model, while aerobic exercise in water was used as an exercise intervention method in animal models. The potential mechanism of action of an exercise intervention on diaphragm dysfunction in COPD was explored by comparing the changes in pulmonary function, diaphragm muscle strength and diaphragm differential metabolites between three groups: A COPD + exercise group (CEG); COPD model group (CMG); and control group (CG). Gas chromatography tandem time-of-flight mass spectrometry (GC-TOF-MS) was used to detect the different metabolites in the diaphragm tissues of rats of the different groups.

\section{Materials and methods}

Animals and management. Healthy male 2-month-old Sprague-Dawley rats with an average body weight of $200 \pm 20 \mathrm{~g}$ were purchased from Beijing Vital River Laboratory Animal Technology Co., Ltd. All the experimental animals had ad libitum access to food and water in a 12:12 h light:dark cycle. The temperature in the feeding room was maintained at $21 \pm 2{ }^{\circ} \mathrm{C}$ and the humidity was stable at $60 \pm 5 \%$. The experimental protocol was approved by the Institutional Animal Care and Use Committee of Shanghai University of Sport (approval no. 2018026), and was conducted following the Animal Research Guidelines of the Shanghai University of Sport. During the experiment, all rats were anesthetized and executed according to the experimental scheme, and all measures were taken to decrease the pain of the experimental animals.

Establishment and verification of the COPD model. A total of 38 rats (Fig. 1) were randomly divided into two groups: COPD rats $(C R ; n=24)$ and $C G(n=14)$. Animals from the $C R$ group were exposed to cigarette smoke for 16 weeks to establish a COPD model, while the CG rats were exposed to fresh air and did not undergo any intervention. The passive smoking poisoning system (PAB-S200; Beijing Bestlab High-Tech Co., Ltd.) was used to generate and expose the animals to cigarette smoke during the experimental process. The method for establishing the model was based on those previously described (24-26,30,31). The similar total number of cigarettes, as described by Caron et al (31), was adopted in the present study, and the modeling duration was shortened to 16 weeks, using progressive CSE. A total of 20 rats were placed in the passive smoking poisoning system at a time. The establishment of the model was completed in 4 stages. The first week was the adaptive modeling period: For 7 days, the rats were 


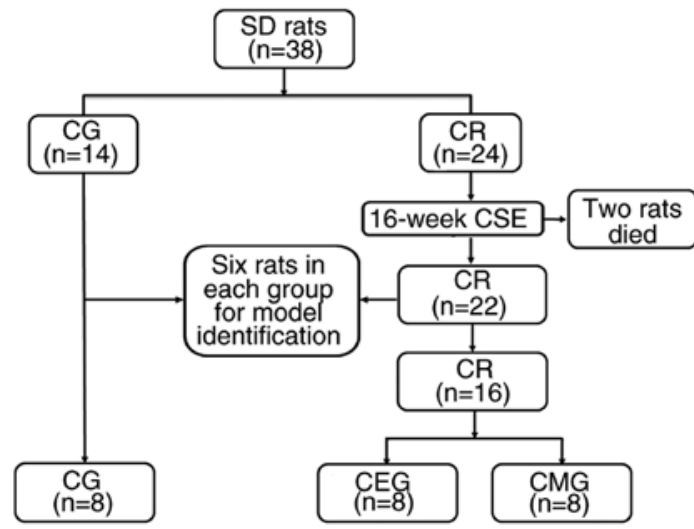

Figure 1. Flow chart of animal grouping. SD rats, Sprague-Dawley rats; CSE, cigarette smoke exposure; COPD, chronic obstructive pulmonary disease; CR, COPD rats; CG, control group; CMG, COPD model group; CEG, $\mathrm{COPD}+$ exercise group.

passively exposed to a dose of smoke from 10 cigarettes once a day for $1 \mathrm{~h}$. During weeks 2-8, the rats received twice the daily dose of smoking, in which 10 cigarettes were burned during each exposure for $1 \mathrm{~h}$. From weeks 9-12, rats were exposed to smoke twice a day, in which 15 cigarettes were burned each time for $1 \mathrm{~h}$. In weeks 13-16, rats were exposed to smoke twice a day, in which 20 cigarettes were burned each time for $1 \mathrm{~h}$. A total of 2 rats died of acute respiratory tract inflammation during the establishment of the model.

A total of 6 rats in CR were randomly selected and compared with $6 \mathrm{CG}$ rats to validate the COPD model after 4 months of smoke exposure. The main parameters of model validation were pulmonary function tests and histological changes in the lung tissues. The pulmonary function procedure was as follows: Rats were weighed and anesthetized using intraperitoneal injection of $10 \%$ chloral hydrate $(400 \mathrm{mg} / \mathrm{kg}$ body weight; Sinopharm Chemical Reagent Co., Ltd.) solution. A total of 10 min later, the righting reflex disappeared and the response to pain stimulus disappeared. Rats entered a deep anesthesia state without peritonitis symptoms, such as abdominal muscle tension. Following skin preparation, the neck skin was cut longitudinally. The subcutaneous tissue and sternohyoid muscle were separated, and the trachea was exposed. The trachea was then cut, and the rats were intubated and connected to the Buxco Pulmonary Function Testing System (Data Sciences International). Forced vital capacity (FVC), 100 milliseconds forced expiratory volume (FEV100), functional residual capacity (FRC), vital capacity (VC) and peak expiratory flow (PEF) were used to identify the lung function.

Following the pulmonary function test, rats were euthanized by rapid decapitation under deep anesthesia. The heartbeat and nerve reflex were then examined to ensure rat death: Cardiac arrest and loss of the nerve reflex were used as confirmation of animal death. The lung lobes of the rats were removed for histological observation to confirm pathological changes. The lung tissues were fixed in $4 \%$ paraformaldehyde for $24 \mathrm{~h}$ at room temperature and dehydrated using an increasing ethanol gradient. Then, the lungs were submerged in xylene, and embedded in paraffin using the Leica EG1160 paraffin embedding machine (Leica Microsystems $\mathrm{GmbH}$ ).
Serial sagittal sections $(5 \mu \mathrm{m})$ were obtained for histological analyses using the Leica RM2235 paraffin microtome (Leica Microsystems $\mathrm{GmbH}$ ). Finally, the lung tissues were stained with hematoxylin \& eosin and observed using a light microscope (magnification, x200).

Training protocols. Following model identification, the remaining COPD rats $(\mathrm{n}=16)$ were randomly divided into $\mathrm{CEG}$ $(\mathrm{n}=8)$ and $\mathrm{CMG}(\mathrm{n}=8)$. The CEG rats underwent aerobic exercise intervention for the subsequent 9 weeks, while the $\mathrm{CMG}$ and $\mathrm{CG}$ rats did not.

The original training program was described by Totou et al (32), and was subsequently modified in the present study. Swimming was used as aerobic exercise, taking place in a tank. The water level was initially set at $45 \mathrm{~cm}$, and then adjusted according to the growth of the animals and the water temperature was set at $33-35^{\circ} \mathrm{C}$. Swimming training included a 60 min swimming course. The whole intervention process was divided into 3 stages. The 17th week was the adaptive intervention stage. On the first day, swimming training lasted $10 \mathrm{~min}$, and was then increased for $10 \mathrm{~min}$ every day until it reached $60 \mathrm{~min}$ on the 5 th day. The training lasted for 6 days. Starting from the 18th week, training was conducted every other day, 3 days a week. At weeks 18-21, rats underwent swimming sessions without load, while at weeks $22-25$, rats gradually adapted to a body mass overload of 5\%. The present study aimed to set the intensity of exercise to near the sub-maximum, according to maximal lactate steady states ( $6 \%$ of body weight for swimming load) noted in the literature (33). Stage-by-stage exercise intervention was beneficial for the rats, to ensure gradual adaption to the intensity of the exercise and to decrease the adverse effects caused by sudden increases in exercise intensity. During the experiment, the rats were progressively challenged with exercises at a higher intensity compared with that of the exercises they had just become adapted to, as once the rats adapt to the intensity of the exercise, the effects of the intervention are not reliable.

Evaluation of pulmonary function and diaphragm function. In the 26th week, the pulmonary function, as aforementioned, and diaphragm function were evaluated in all rats. The isolated diaphragm muscle strength, measured in a tissue perfusion system (Harvard Apparatus), was used to reflect the diaphragm function in rats, as described previously (34). Following thoracotomy, $1.5 \times 9.0 \mathrm{~mm}$ diaphragm strips were cut from the edge of a blood vessel perpendicular to the left side and the middle of the diaphragm and placed into Krebs-Hanseleit buffer $\left(117 \mathrm{mmol} / \mathrm{l} \mathrm{NaCl}, 4.7 \mathrm{mmol} / 1 \mathrm{KCl}, 2.5 \mathrm{mmol} / \mathrm{l} \mathrm{CaCl}_{2}\right.$, $1.2 \mathrm{mmol} / 1 \mathrm{KH}_{2} \mathrm{PO}_{4}, 1.2 \mathrm{mmol} / 1 \mathrm{MgSO}_{4}, 24.6 \mathrm{mmol} / \mathrm{l} \mathrm{NaHCO}$ and, $10.1 \mathrm{mmol} / 1 \mathrm{D}$-glucose) at $37^{\circ} \mathrm{C}$. The mixture of $95 \% \mathrm{O}_{2}$ and $5 \% \mathrm{CO}_{2}$ was used to balance the perfusion fluid for $15 \mathrm{~min}$ prior to perfusion, and the gas flow was maintained during the perfusion. After a $2 \mathrm{~g}$ weight preload calibration, the diaphragm tissue strips were put into the glass bath; one end of the strip was fixed at the bottom of the bath and the other end of the strip was attached to the tension sensor. A tungsten wire electrode was used to stimulate the muscle strip at $10 \mathrm{~V}$ with a square wave of $1 \mathrm{~Hz}$ and $2 \mathrm{~ms}$ wavelength along the long axis of the muscle. The diaphragm contraction strength was recorded using PowerLab 4/35 data acquisition hardware 
(ADInstruments Ltd.). The mean values of the 5 maximum peaks of muscle contraction were measured and corrected by the cross-sectional area (CSA) in $\mathrm{mg} / \mathrm{cm}^{2}$. Following the measurement of diaphragm strength in vitro, the non-muscle tissue was removed, and the length of the muscle strip was measured. The water was removed with absorbent filter paper, and the muscle strip was weighed. CSA was calculated using the following formula: CSA $\left(\mathrm{mm}^{2}\right)=$ strip weight $(\mathrm{mg}) /[\mathrm{strip}$ length $(\mathrm{mm})$ x muscle density $105.6(\mathrm{mg} / \mathrm{mm})]$.

The histological observations of the lung and diaphragm were also performed as aforementioned. In addition, the lung tissues of the three groups of rats were stained using a reticulin kit (Genmed Scientifics, Inc.) to further observe the structure of alveoli. The specific steps are described in a previous study (35). Briefly, sections were cut at a 5- $\mu \mathrm{m}$ thickness from routinely processed paraffin blocks. They were deparaffinized, rehydrated, rinsed in distilled water, and immersed in $1 \%$ potassium permanganate $(2 \mathrm{~min})$. The sections were rinsed in the following solutions: $2.5 \%$ oxalic acid $(1 \mathrm{~min}), 2 \%$ iron alum (1 min), Gomori's solution (3 min), 10\% formalin ( $2 \mathrm{~min}$ ), gold chloride (1:500; $5 \mathrm{~min}$ ), $3 \%$ potassium metabisulfite $(1 \mathrm{~min})$, and $3 \%$ sodium thiosulfate $(1 \mathrm{~min})$; sections were rinsed with distilled water before immersion in each solution. Then, the sections were dehydrated with a graded series of ethanol, cleared in xylene, and fixed with neutral gum. The above operations were performed in a dark room at room temperature.

Sample preparation. The remaining diaphragm muscle tissues of rats were collected and $50 \pm 1 \mathrm{mg}$ diaphragm tissue was extracted for metabolomic analysis. The samples were placed into $2 \mathrm{ml}$ Eppendorf (EP) tubes and $450 \mu \mathrm{l}$ extraction liquid $\left(\mathrm{V}_{\text {Methanol }}: \mathrm{V}_{\text {Chloroform }}=3: 1\right)$ was then added. A total of $10 \mu \mathrm{l}$ L-2-chlorophenylalanine $(1 \mathrm{mg} / \mathrm{ml}$ stock in double-distilled $\mathrm{H}_{2} \mathrm{O}$; Shanghai Hengbai Biotech Co., Ltd.) was used as the internal standard. The mix was vortexed for $30 \mathrm{sec}$, homogenized in a ball mill for $4 \mathrm{~min}$ at $45 \mathrm{~Hz}$, and ultrasound-treated at $40 \mathrm{kHz}$ for $5 \mathrm{~min}$. The sample was incubated in ice water during the ultrasound treatment. Then, the sample was centrifuged at $13,800 \mathrm{x}$ g for $15 \mathrm{~min}$ at $4^{\circ} \mathrm{C}$, and $300 \mu \mathrm{l}$ supernatant was transferred into a fresh $1.5 \mathrm{ml}$ EP tube. A total of $50 \mu \mathrm{l}$ from each sample was taken and pooled as the QC sample, which was dried completely in a vacuum concentrator without heating. Then, $40 \mu 1$ methoxyamination hydrochloride [20 $\mathrm{mg} / \mathrm{ml}$ in pyridine; TCI (Shanghai) Development Co., Ltd.] was added, and the QC sample was incubated for $30 \mathrm{~min}$ at $80^{\circ} \mathrm{C}$. Afterward, $60 \mu \mathrm{BSTFA}$ regent $(1 \%$ trimethyl chlorosilane, v/v; Regis Technologies, Inc.) was added to the QC sample, which was further incubated for $1.5 \mathrm{~h}$ at $70^{\circ} \mathrm{C}$. A total of $5 \mu \mathrm{l}$ FAMEs (in chloroform; Dr. Ehrenstorfer $\mathrm{GmbH}$ ) was added to the QC sample while cooling to room temperature. All samples were analyzed by a gas chromatography system coupled with a Pegasus HT time-of-flight mass spectrometer (GC-TOF-MS).

GC-TOF-MS analysis. GC-TOF-MS analysis was performed using an Agilent 7890 gas chromatograph system (Agilent Technologies, Inc.) coupled with a Pegasus ${ }^{\circledR}$ HT time-of-flight mass spectrometer (LECO Corporation). The system utilized a DB-5MS capillary column (Agilent Technologies, Inc.) coated with 5\% diphenyl cross-linked with 95\% dimethylpolysiloxane (30 $\mathrm{m} \times 250 \mu \mathrm{m}$ inner diameter, $0.25 \mu \mathrm{m}$ film thickness; J\&W Scientific). A $1 \mu \mathrm{l}$ aliquot of the analyte was injected in the splitless mode. Helium was used as the carrier gas, the front inlet purge flow was $3 \mathrm{ml} \mathrm{min}^{-1}$, and the gas flow rate through the column was $1 \mathrm{ml} \mathrm{min}$. The initial temperature was maintained at $50^{\circ} \mathrm{C}$ for $1 \mathrm{~min}$, and it was then raised to $310^{\circ} \mathrm{C}$ at a rate of $10^{\circ} \mathrm{C} \mathrm{m^{-1 }}$ and subsequently maintained at $310^{\circ} \mathrm{C}$ for $8 \mathrm{~min}$. The injection, transfer line, and ion source temperatures were 280,280 and $250^{\circ} \mathrm{C}$, respectively. The energy was $-70 \mathrm{eV}$ in the electron impact mode. The mass spectrometry data were acquired in full-scan mode with the $\mathrm{m} / \mathrm{z}$ range of 50-500 at a rate of 12.5 spectra/second following a solvent delay of $6.17 \mathrm{~min}$.

\section{Data preprocessing}

Pulmonary function and muscle strength in vitro. The data distribution was examined by the Kolmogorov-Smirnov test and homogeneity test of variance (Levene's test). The normally distributed data are expressed as mean \pm standard deviation, while skewed data are expressed as median (interquartile range). A one-way analysis of variance was used for comparisons among multiple groups, and the Least Significant Difference method was used for further comparison. Dunnett's T3 was used for multiple comparisons among groups if the variance was not uniform. $\mathrm{P}<0.05$ was considered to indicate a statistically significant difference. The software package SPSS v.21.0 (IBM Corp) was used for statistical analyses.

Metabolomics results processing. Chroma TOF 4.3X software (LECO Corporation) and LECO-Fiehn Rtx 5 database were used for raw peaks exacting, the data baselines filtering and calibration of the baseline, peak alignment, deconvolution analysis, peak identification and integration of the peak area (36). Both the mass spectrum match and retention index match values were measured during metabolite identification. Peaks detected in $<50 \%$ of QC samples or RSD $>30 \%$ in QC samples were removed, as described previously (37).

The original data were preprocessed. The deviation values were filtered, and the missing values in the original data were simulated. Finally, the data were standardized using the internal standard. Following processing, the three-dimensional data associated with peak number, sample name and standardized peak area were input into SIMCA v.14.1 software package (MKS Instruments, Inc.) for the orthogonal projection of principal component analysis (PCA) and orthogonal projections to latent structures-discriminant analysis (OPLS-DA). PCA revealed the internal structure of data. Concomitantly, OPLS-DA was used to improve visualization and for follow-up analysis of the differential variables identified in the large metabolomics dataset. In addition, univariate statistical analysis was used for data analysis to avoid false-positive errors or model over-fitting caused by using only one type of statistical analysis. The variable importance for the projection (VIP) $>1.0$ and $\mathrm{P}<0.05$ were used as the cut-off values for significantly different metabolites.

Differential metabolites obtained from the analysis were identified to be biologically similar or complementary in functions, or regulated positively or negatively by the same 
A

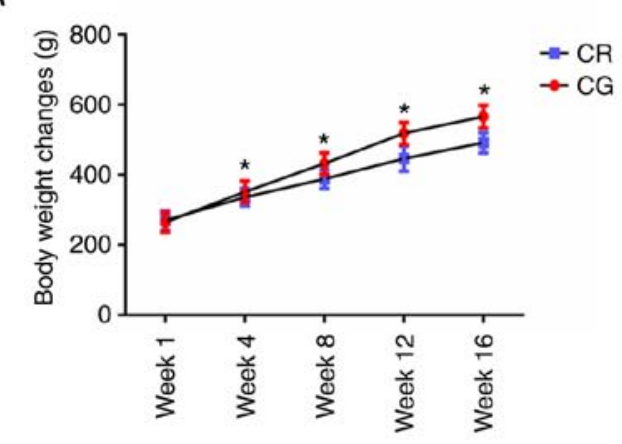

C

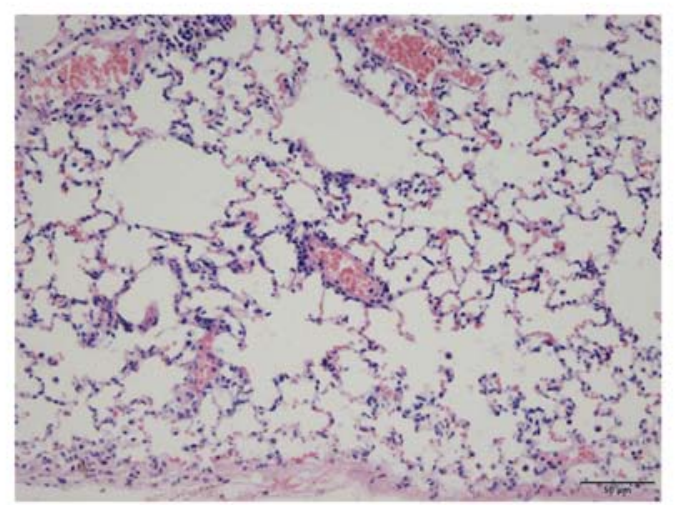

B

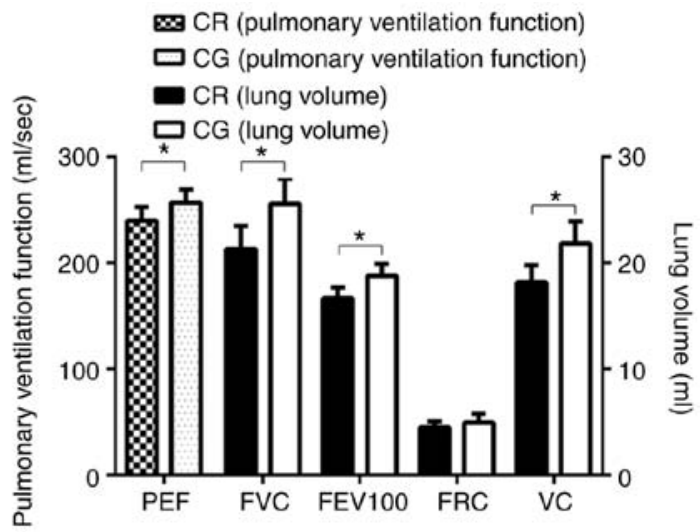

D

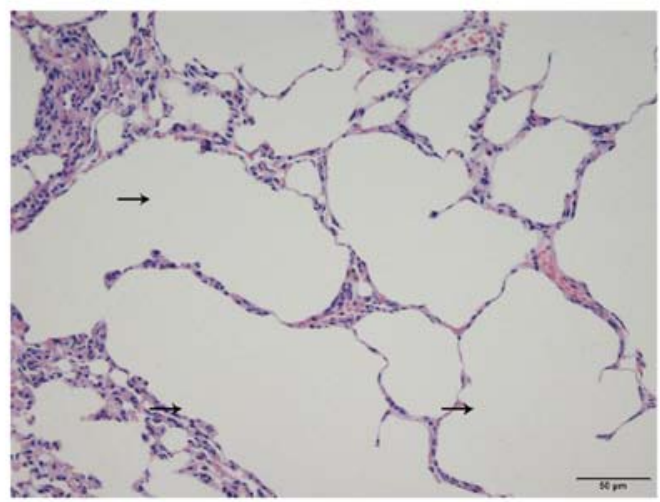

Figure 2. Bodyweight and pulmonary function and structure following model establishment. (A) Weight change during model establishment. (B) Comparison of pulmonary function between model rats and CG. (C) Pulmonary structure in CG. Scale bar=50 $\mu$ m. (D) Pulmonary structure in model rats. Scale bar $=50 \mu \mathrm{m}$. The black arrows indicate the enlarged alveoli. " $\mathrm{P}<0.05$. PEF, peak expiratory flow; FVC, forced vital capacity; FEV100, 100 milliseconds forced expiratory volume; FRC, functional residual capacity; VC, vital capacity; peak expiratory flow; CR, chronic obstructive pulmonary disease rats; CG, control group.

metabolic pathway, showing either similar or opposing expression profiles among the different experimental groups. Therefore, a hierarchical cluster analysis of the differentiated metabolites was performed using Euclidean distance matrix (MATLAB 2018b; https://www.mathworks.com/), as described previously (38). Moreover, the annotations identified from the Kyoto Encyclopedia of Genes and Genomes $(39,40)$ (KEGG; https://www.genome.jp/kegg/) were analyzed, and the metabolic pathways of differentiated metabolites were further analyzed using MetaboAnalyst 3.0 (https://www. metaboanalyst.ca).

\section{Results}

Effect of 16-week CSE on pulmonary function and tissue structure in rats. The results of model verification demonstrated that there were significant differences in lung function and structure between the COPD rats and control rats, which suggested that the model was successfully established (Fig. 2). The 16-week model-building process inhibited weight gain of the model rats (Fig. 2A). The pulmonary ventilation function of model rats decreased significantly, including PEF, FEV100 and FVC (Fig. 2B). Concomitantly, the histological examination demonstrated that, compared with the control rats (Fig. 2C), the pulmonary structure of the model rats was reconstructed: the alveoli were enlarged, and fusions between the terminal bronchus and the alveoli were observed (Fig. 2D).
Changes in pulmonary function and histology following exercise. The effects of the CSE treatment on the respiratory tract and the general condition of rats were different between the treatment groups. During the entire study, the animals in the CG were allowed to move freely for an extended period of time, with good breathing conditions, a smooth coat and gradual weight gain. The COPD model animals (CEG and $\mathrm{CMG}$ ) were affected by cigarette smoke during the modeling period (0-16 weeks). Their fur was dry and yellowish, and they exhibited symptoms of respiratory discomfort, including shortness of breath, hypersonic breathing and increased secretions of the respiratory tract. The weight of the model animals increased slowly. During the intervention period (17-25 weeks), the respiratory symptoms of CEG and CMG gradually disappeared, but the weight gain of CEG rats was slow. In addition, the 9-week swimming intervention significantly improved the lung function in the COPD rats: Compared with the CMG, the pulmonary function of CEG was significantly improved $(\mathrm{P}<0.05)$, and there were increases in FVC, FEV100 and PEF values. Furthermore, the difference between $\mathrm{CEG}$ and $\mathrm{CG}$ was primarily reflected in the decrease of $\mathrm{FRC}(\mathrm{P}<0.05$; Fig. 3A).

Histological staining of lung tissue demonstrated a significant difference among the three groups following intervention. In the $\mathrm{CMG}$, alveolar dilatation, narrowing and rupture of alveolar septum were observed under microscopy, and the adjacent alveoli had fused into larger cysts (Fig. 3B). The morphological structure of lung tissue in CEG was similar 
A $\approx \mathrm{CMG}$ (pulmonary ventilation function)

曰CEG (pulmonary ventilation function)

$\square C G$ (pulmonary ventilation function)

- CMG (lung volume)

क्ष $\triangle \mathrm{CEG}$ (lung volume)

$\square C G$ (lung volume)

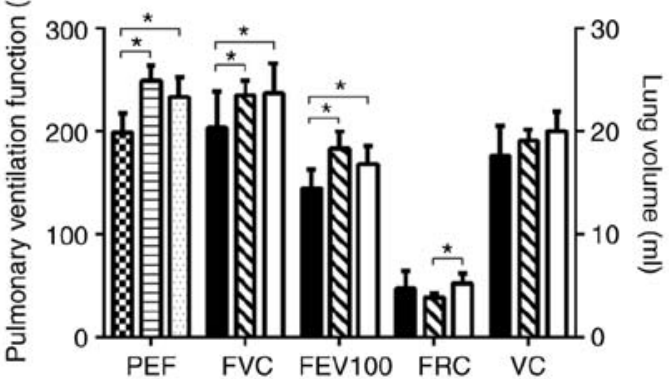

C

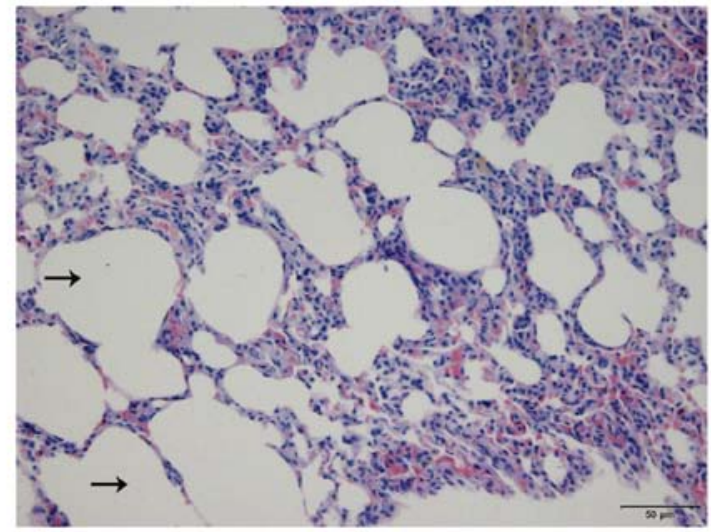

B

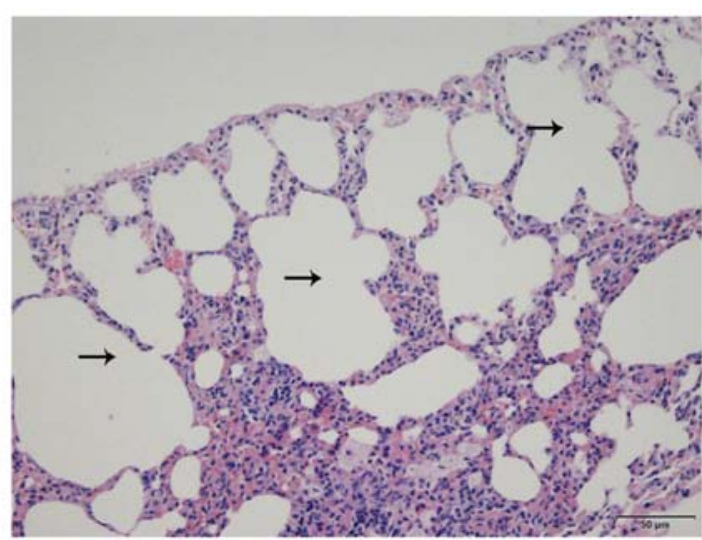

D

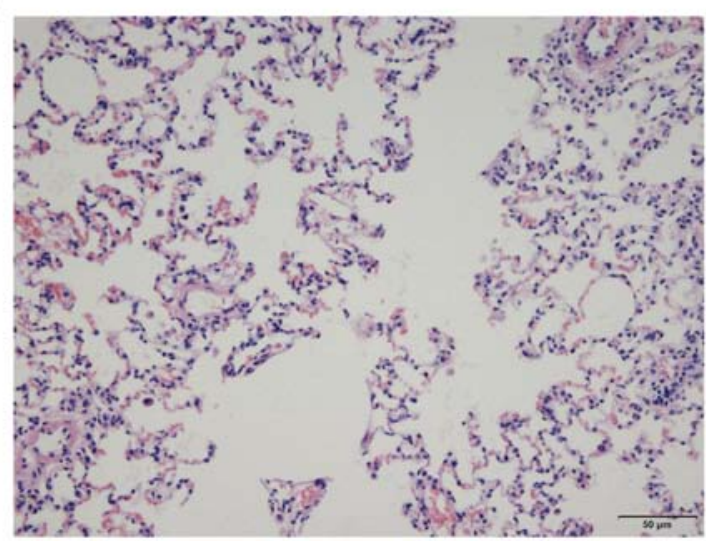

Figure 3. Pulmonary function and histological changes following intervention. (A) Comparison of pulmonary function of rats in each group following intervention. (B) Histological structure of CMG lung tissues. The black arrows indicate the enlarged alveoli. Scale bar=50 $\mu \mathrm{m}$. (C) Histological structure of CEG lung tissues. The black arrows indicate the enlarged alveoli. Scale bar=50 $\mu \mathrm{m}$. (D) Histological structure of CG lung tissues. Scale bar=50 $\mu \mathrm{m}$. ${ }^{*} \mathrm{P}<0.05$. PEF, peak expiratory flow; FVC, forced vital capacity; FEV100, 100 milliseconds forced expiratory volume; FRC, functional residual capacity; VC, vital capacity; peak expiratory flow; COPD, chronic obstructive pulmonary disease; CMG, COPD model group; CEG, COPD + exercise group; CG, control group.

to that in the CMG (Fig. 3C). In the CG, the rats exhibited healthy lung tissue structure with uniform alveolar size and within a reasonable range (Fig. 3D). As it was not possible to determine under the microscope whether the dark stained sections were aggregated inflammatory cells, the effect of an exercise intervention on the inflammatory response could not be determined under the microscope. The reticulin stained results are presented as supplementary materials (Fig. S1).

Effects of aerobic exercise on diaphragm muscle strength and histology in rats. The measurement of the diaphragm muscle strength in vitro closely reflected the contractile function of the diaphragm, and the results of the present study indicated that aerobic exercise improved the diaphragm function of COPD rats. It was demonstrated that the diaphragm muscle strength of the CMG was significantly weaker compared with that of the CG $(\mathrm{P}<0.05)$, and the diaphragm muscle strength of CEG rats was stronger compared with that of the CMG $(\mathrm{P}<0.05)$. There was no significant difference in diaphragm muscle strength between the CEG and CG (Fig. 4A). The diaphragms of the three groups of rats exhibited different histological morphologies. In the CMG, the structure of muscle fibers in the longitudinal section of the diaphragm was not uniform, and the muscle fibers were not close together (Fig. 4B). The proliferation of interstitial fibers could be observed in certain visual fields. In turn, the muscle fibers in the CEG (Fig. 4C) and the CG (Fig. 4D) were arranged neatly and tightly, and no interstitial fibers and capillary proliferation were observed.

Multivariate analysis of the metabolomics data. Of the 24 samples, 742 peaks were extracted from the original data. Following data preprocessing, 599 peaks remained. The results of the multivariate pattern recognition analysis indicated that the data were reliable. Firstly, from the results of the PCA score chart, all the samples were in the $95 \%$ Hotelling's T-squared ellipse, with the exception of one outlier (Fig. 5). Secondly, OPLS-DA was used to analyze the model (Fig. 6) to obtain more reliable information about the correlation between the significantly different metabolites and the experimental groups. The OPLS-DA score plot demonstrated significantly separated clusters between the three different groups, although a sample from the CMG was not in the 95\% Hotelling's T-squared ellipse in 2 comparisons (Fig. 6A and B). Compared with the CG, the two evaluating parameters of the OPLS-DA model were $R^{2} Y=0.902$ and $\mathrm{Q}^{2}=0.523$. Compared with $\mathrm{CMG}$, the parameters were $\mathrm{R}^{2} \mathrm{Y}=0.956$ and $\mathrm{Q}^{2}=0.584$. Fig. $6 \mathrm{C}$ demonstrates the results from 200 permutation tests, with intercept $R^{2}=(0,0.82)$ 
A
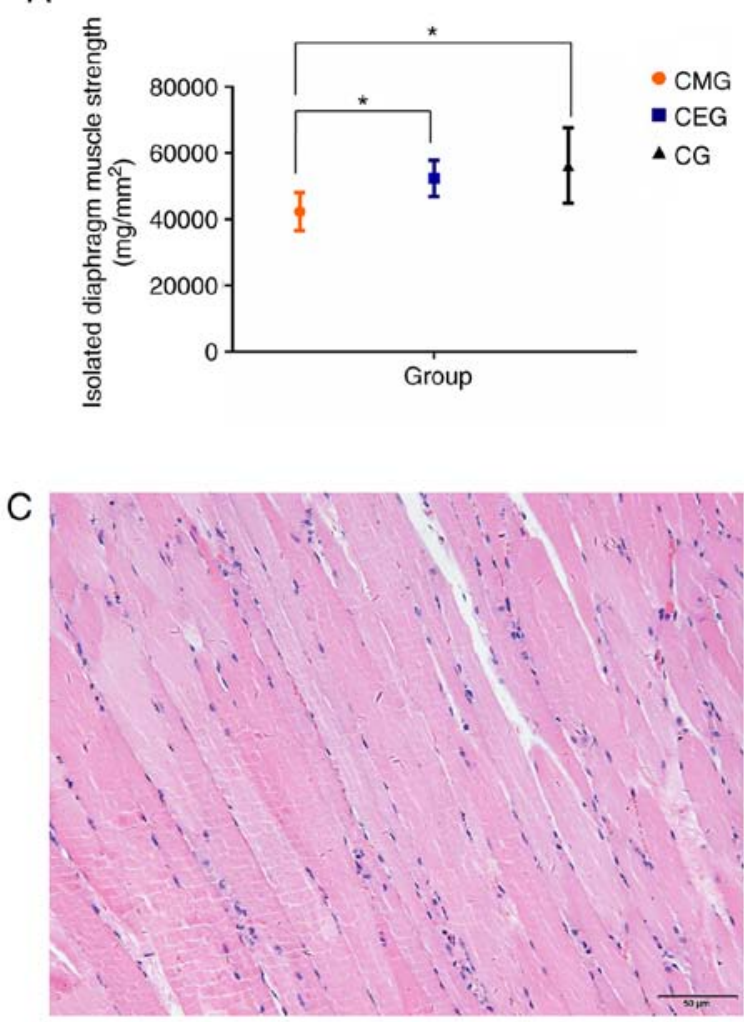

B
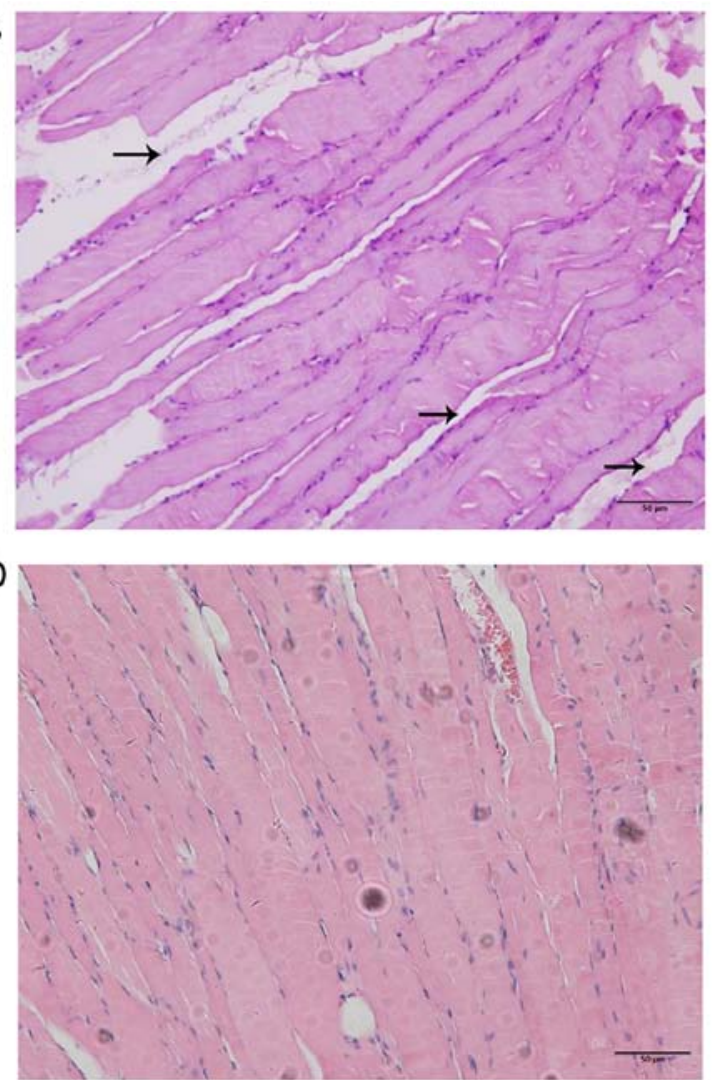

Figure 4. Changes in diaphragm muscle strength and histology after the intervention. (A) Diaphragm strength among three different groups following intervention. (B) Histological observations of the diaphragm tissues in the CMG. The black arrows indicate the enlarged muscle fiber gaps. Scale bar=50 $\mu \mathrm{m}$. (C) Histological observations of the diaphragm tissues in the CEG. Scale bar=50 $\mu \mathrm{m}$. (D) Histological observations of the diaphragm tissues in the CG. Scale bar $=50 \mu \mathrm{m}$. "P<0.05. COPD, chronic obstructive pulmonary disease; CMG, COPD model group; CEG, COPD + exercise group; CG, control group.
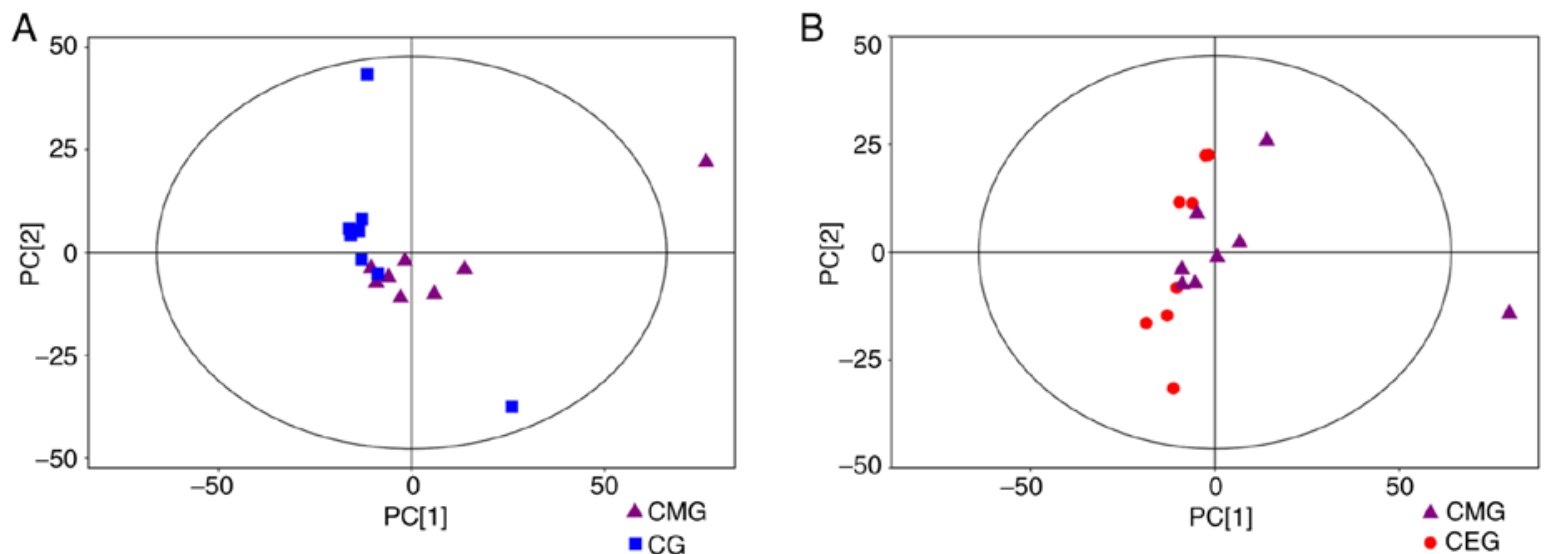

Figure 5. Score scatter plot of the PCA model. (A) Score scatter plot of the PCA model for CG vs. CMG. (B) Score scatter plot of the PCA model for CMG vs. CEG. Most samples in the score plots were within the 95\% Hotelling's T-squared ellipse. PCA, principal component analysis; COPD, chronic obstructive pulmonary disease; $\mathrm{CMG}, \mathrm{COPD}$ model group; $\mathrm{CEG}, \mathrm{COPD}+$ exercise group; $\mathrm{CG}$, control group.

and $\mathrm{Q}^{2}=(0,-0.46)$ in the comparison of the $\mathrm{CMG}$ and the $\mathrm{CG}$, while Fig. 6D shows the permutation test results of the comparison between the CEG and $\mathrm{CMG}$, with intercept $\mathrm{R}^{2}=(0,0.85)$ and $\mathrm{Q}^{2}=(0,-0.45)$. These results confirmed that the original model had good robustness and that there was no over-fitting phenomenon, indicating that the model was appropriate for follow-up analysis. Therefore, the outlier was retained in subsequent analysis, given that the results of multivariate analysis were stable and reliable.
Biomarkers associated with exercise intervention. The distribution of all differential metabolites was grouped into upregulated and downregulated metabolites. Compared with the diaphragm metabolites of the $\mathrm{CMG}$ and the $\mathrm{CG}$, 85 different metabolites were screened out, of which 82 metabolites were identified as downregulated. In the comparison between CEG and CMG, 80 different metabolites were identified, 77 of which were identified as upregulated. The screened differential metabolites are presented in the form 

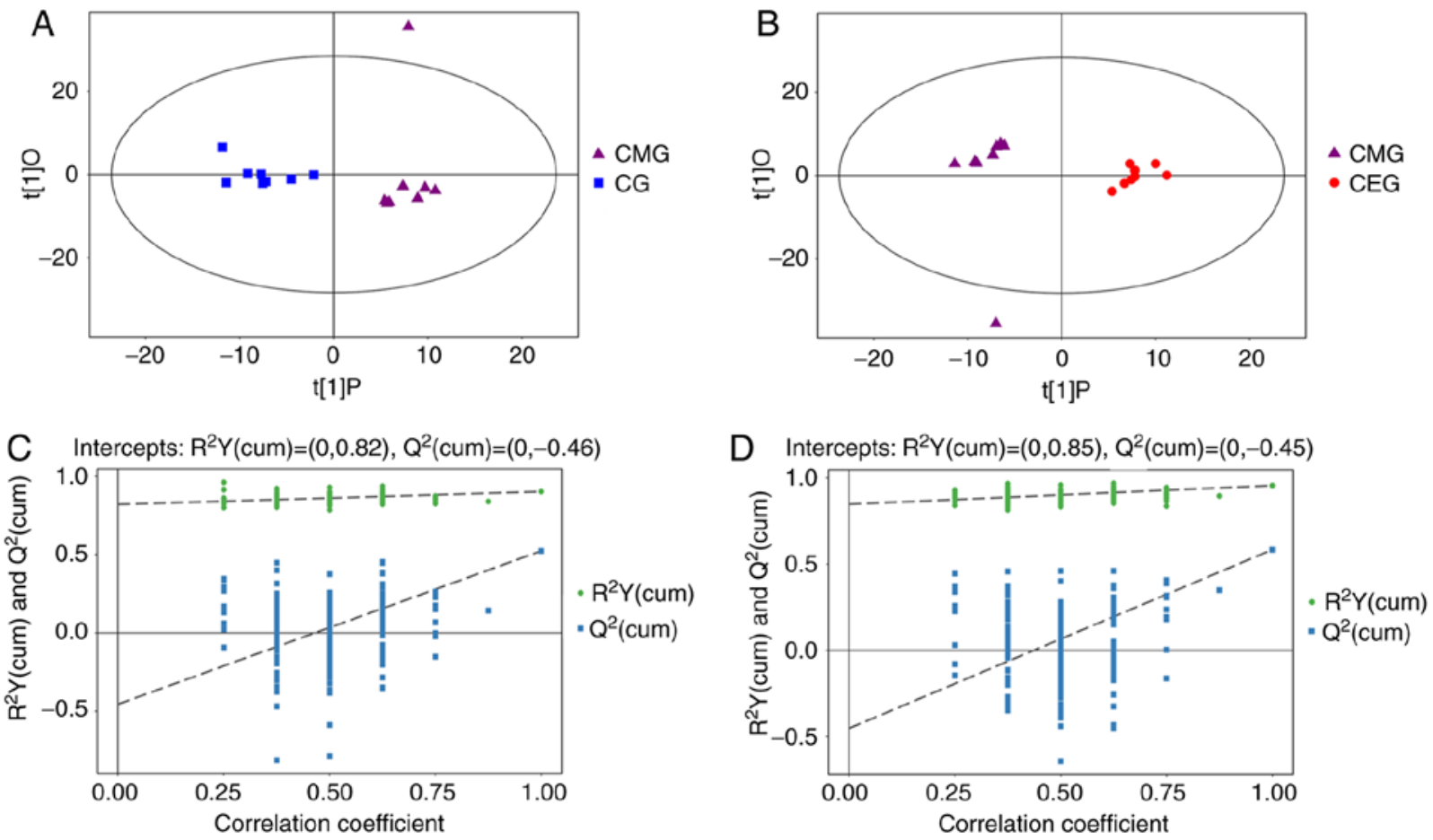

Figure 6. Results of OPLS-DA. (A) Score scatter plot of the OPLS-DA model for CG vs. CMG. (B) Score scatter plot of the OPLS-DA model for CMG vs. CEG. (C) Permutation test of the OPLS-DA model for CG vs. CMG. (D) Permutation test of the OPLS-DA model for CMG vs. CEG. CMG, COPD model group; CEG, COPD plus exercise group; CG, control group; OPLS-DA, orthogonal projections to latent structures-discriminant analysis; COPD, chronic obstructive pulmonary disease; CMG, COPD model group; CEG, COPD + exercise group; CG, control group.
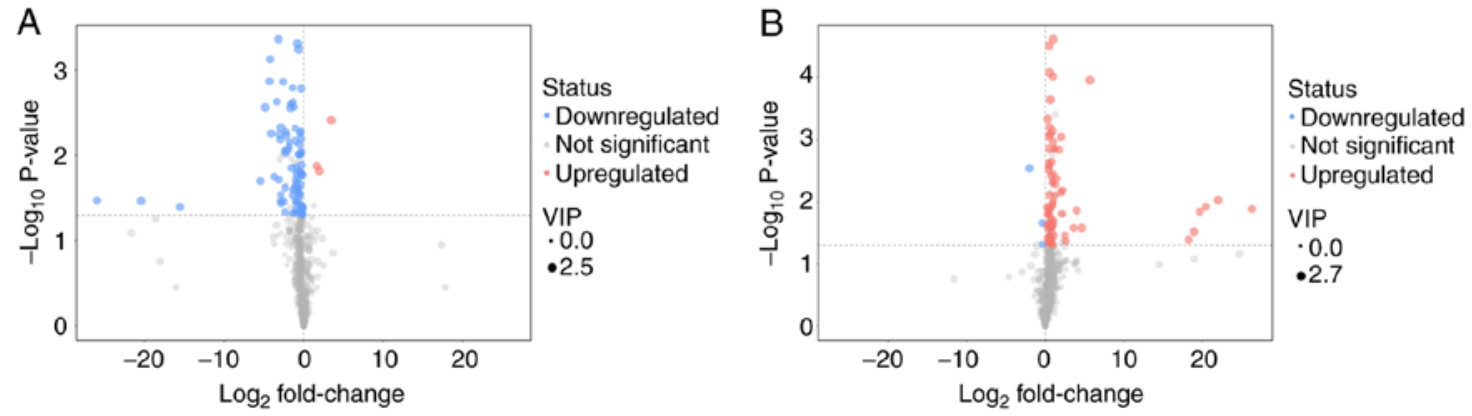

Figure 7. Volcano plot. (A) Volcano plot for CG vs. CMG. (B) Volcano plot for CMG vs. CEG. VIP, Variable Importance in the Projection; COPD, chronic obstructive pulmonary disease; CMG, COPD model group; CEG, COPD + exercise group; CG, control group.

of volcano plots (Fig. 7). Compared with the CG, excluding unknown metabolites, 36 metabolites in the diaphragm of the CMG were identified to be significantly different. In addition, compared with the CMG, the expression of 29 metabolites in the diaphragm of rats in CEG was significantly different following exercise intervention. To identify any candidate biomarkers associated with exercise training, the differentially expressed metabolites that exhibited contrasting expression profiles between the $\mathrm{CMG}$ and the $\mathrm{CG}$, and between the CEG and the CMG, were selected. A total of 8 metabolites were identified (Table I), including threonine, serine, nicotinamide, lactic acid, citraconic acid, 3-cyanoalanine, dioctyl phthalate and 2-hydroxypyridine.

Pathway analysis of biomarkers. The Euclidean distance matrix was used for differential metabolite analysis, to explore the correlation between the different metabolites identified and to explore the characteristics of metabolite changes among experimental groups (Fig. 8). In addition, KEGG annotation of differential metabolites and pathway analysis of differential metabolites were employed for further analysis, considering the complex metabolic reactions and associated regulatory mechanisms. When the metabolites different in CMG and CG were analyzed using MetaboAnalyst, 17 metabolite pathways were identified to be significant. Based on their-ln (P-value) and pathway impact scores [-ln (P-value) $>1$ and impact scores $>0$ ] and the biological roles of metabolic pathways in associated fields, five pathways were selected. These were: Arginine and proline metabolism; nicotinate and nicotinamide metabolism; tricarboxylic acid cycle; starch and sucrose metabolism; and galactose metabolism (Fig. 9A). A total of 4 metabolite pathways were identified to be significantly different between CEG and CMG: Pyrimidine metabolism; arginine and proline metabolism; nicotinate and nicotinamide 
Table I. Metabolites with contrasting expression profiles between CMG/CG and CEG/CMG groups.

\begin{tabular}{lcccccc}
\hline Metabolites & $\begin{array}{c}\text { Trends in } \\
\text { CMG/CG }\end{array}$ & $\begin{array}{c}\text { Changing trends } \\
\text { in CEG/CMG }\end{array}$ & $\begin{array}{c}\text { Fold-change } \\
\text { in CMG/CG }\end{array}$ & $\begin{array}{c}\text { P-value } \\
\text { in CMG/CG }\end{array}$ & $\begin{array}{c}\text { Fold-change } \\
\text { in CEG/CMG }\end{array}$ & $\begin{array}{c}\text { P-value in } \\
\text { CEG/CMG }\end{array}$ \\
\hline Threonine & Down & $\mathrm{Up}$ & 0.778 & 0.005 & 1.569 & 0.001 \\
Serine & Down & $\mathrm{Up}$ & 0.275 & 0.007 & 1.433 & 0.001 \\
Nicotinamide & Down & $\mathrm{Up}$ & 0.672 & 0.028 & 1.504 & 0.022 \\
Lactic acid & Down & $\mathrm{Up}$ & 1.507 & 0.033 & 83147489.53 & 0.013 \\
Citraconic acid & Down & $\mathrm{Up}$ & 0.808 & 0.039 & 1.426 & 0.001 \\
2-Hydroxypyridine & Down & $\mathrm{Up}$ & 0.814 & 0.006 & 1.700 & 0.002 \\
3-Cyanoalanine & Down & $\mathrm{Up}$ & 0.656 & 0.009 & 1.451 & 0.002 \\
Dioctyl phthalate & Down & $\mathrm{Up}$ & 0.022 & 0.019 & 24.811 & 0.026 \\
\hline
\end{tabular}

Down, downregulated; Up, upregulated; CMG, COPD model group; CEG, COPD + exercise group; CG, control group.

A

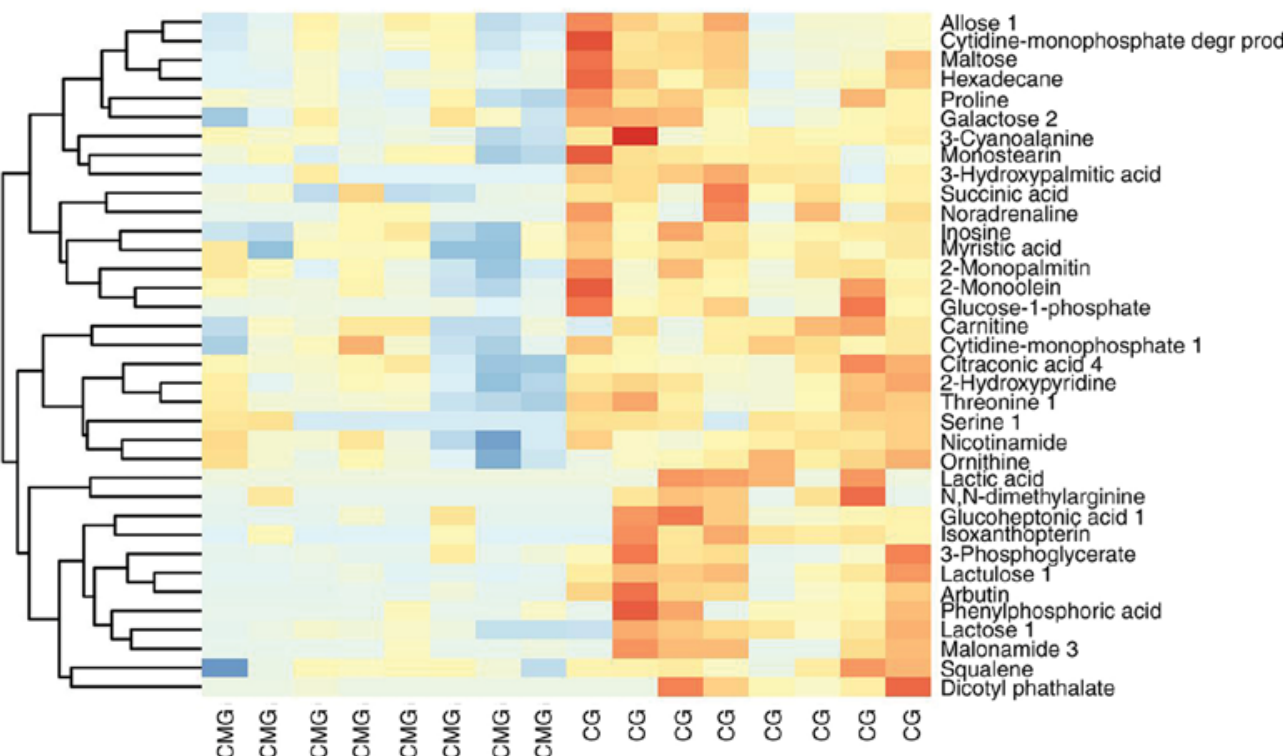

B

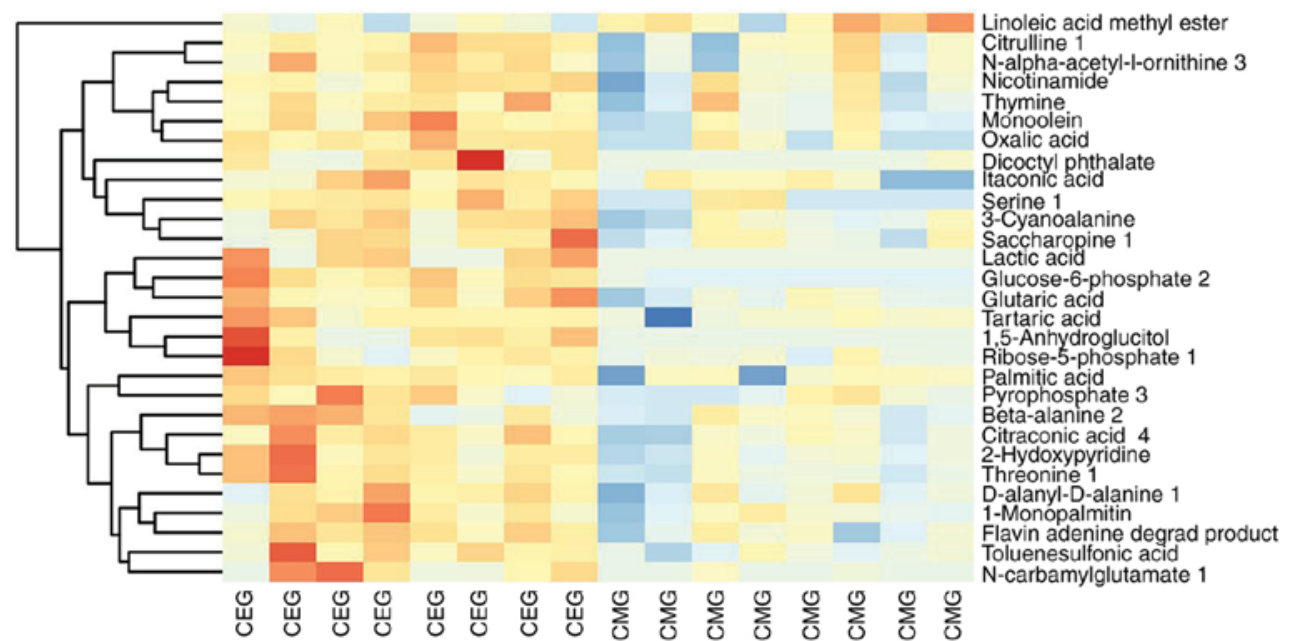

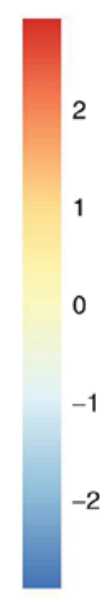

0

$-1$

$-2$

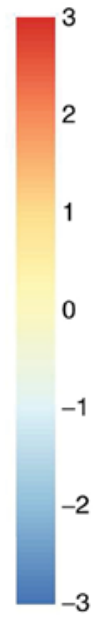

Figure 8. Heatmap of hierarchical clustering analysis. (A) Heatmap of hierarchical clustering analysis for CG vs. CMG. (B) Heatmap of hierarchical clustering analysis for CMG vs. CEG. CMG, COPD model group; CEG, COPD + exercise group; CG, control group.

metabolism; and beta-alanine metabolism (Fig. 9B). Notably, the metabolic pathways that were identified in both comparisons deserve further discussion. The substances in these pathways may contribute to the occurrence of diseases, but they could also be involved in the potential mechanisms underlying the exercise-based improvement of the condition. 

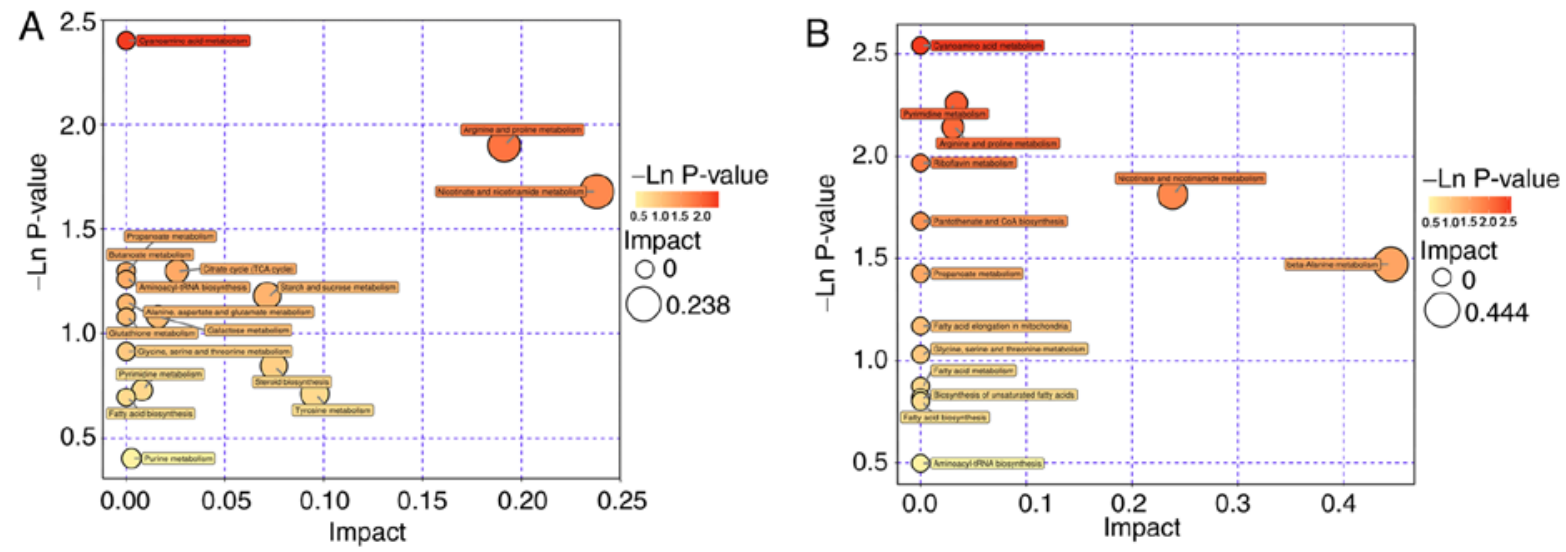

Figure 9. Pathway analysis. (A) Pathway analysis for CG vs. CMG. (B) Pathway analysis for CMG vs. CEG. COPD, chronic obstructive pulmonary disease; CMG, COPD model group; CEG, COPD + exercise group; CG, control group.

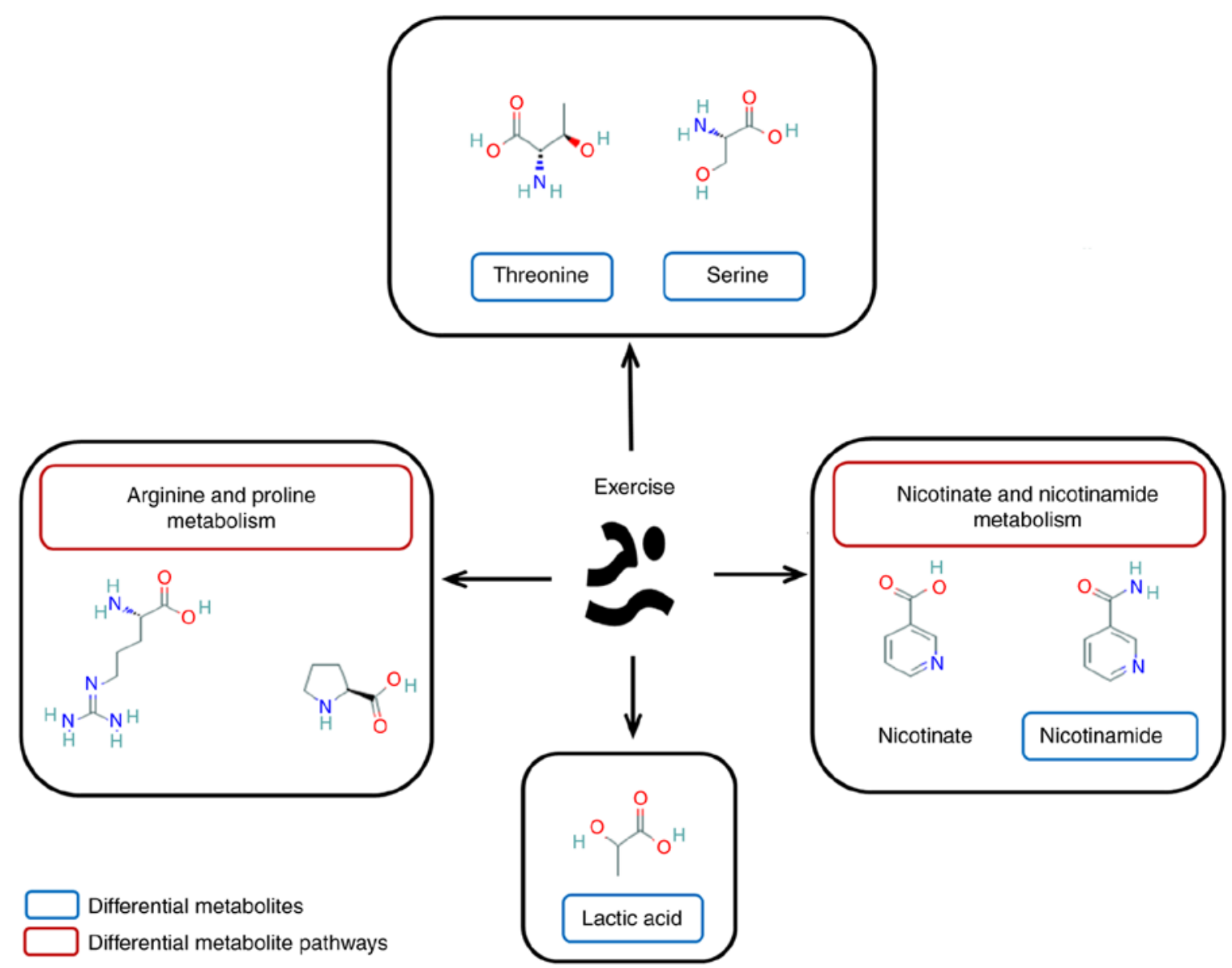

Figure 10. Major metabolites and corresponding pathways affected by exercise. The shared expression of metabolites and their corresponding pathways in separate group comparisons were suggested to be involved in the potential mechanisms of action of exercise-induced diaphragm function enhancement.

Considering the source and function of these metabolites, the exercise-dependent enhancement of diaphragm function in COPD rats is potentially mediated by these shared pathways, namely, the nicotinate and nicotinamide metabolism, and arginine and proline metabolism pathways. In addition, the glycine-serine-threonine metabolism, fatty acid biosynthesis and metabolism-associated pathways also appeared in 2 comparisons, even though the impact scores of these pathways were not high (Fig. 10).

\section{Discussion}

Changes in pulmonary function and histology in COPD rats following exercise. Exercise intervention inhibited the adverse effects of respiratory tract exposure to smoke $(41,42)$ and improved the general condition of rats (43). Considering the association between the modeling process and self-repair and the smoking habits of some patients with COPD [long-term smoking and difficult to quit smoking $(44,45)]$, a progressive 
long-term exposure to cigarette smoke was adopted. Rodents have a demonstrated ability for self-repair (46). Maintaining the intensity of a constant stimulus results in a gradual increase in tolerance and tissue repair $(47,48)$. Incremental exposure to cigarette smoke decreased the effect of self-repair in rats $(49,50)$. Concomitantly, long-term incremental exposure to cigarette smoke also imitates the smoking habits of patients with COPD, compounding the effects of cigarettes on the disease $(30,51)$. Following smoking cessation, the changes in the respiratory symptoms in the CMG reflected the effect of self-repair, while the recovery process in the CEG rats may have benefited from the exercise intervention; the change of pulmonary function results in this group reflected this hypothesis. In addition, in the entire cohort of rats, exercise elicited an effect on the rate of weight gain, revealing that the effect of exercise on the body is multifaceted.

To evaluate the effect of exercise on pulmonary function in COPD rats, the present study primarily focused on the improvement of ventilation function. As the gold standard of COPD diagnosis, the improvement in the pulmonary function has a significant effect on the prognosis of COPD. Clinical pulmonary function examination is primarily divided into two aspects; namely, the examination of lung volume and the examination of pulmonary ventilation function (52). The abnormality of pulmonary function in patients with COPD is reflected in both pulmonary volume and pulmonary ventilation function (53). In patients with COPD, excessive inflation of the lungs results in an increase in the residual volume, which leads to a marked decrease in the ability of inhalation. In pulmonary function tests, abnormal lung capacity was observed, such as decreased complementary expiratory volume, increased residual volume or decreased vital capacity. Airway obstruction, such as decreased ventilation function, is the primary symptom in the lungs of patients with COPD. Abnormal ventilation function can be manifested as a decrease of FVC, forced expiratory volume in the first second or PEF, or an increase of FRC (54).

The results of the pulmonary function tests indicated that FVC, FEV100 and PEF, as indexes of pulmonary ventilation function, were significantly different in the three groups. The difference between the CMG and the CG indicated that the pulmonary ventilation function of CMG did decrease following exposure to cigarette smoke, which was one of the successful manifestations of the establishment of the model. Meanwhile, the difference between the CEG and CMG groups indicated that the ventilation function of the rats was significantly improved following exercise intervention, particularly the FRC and PEF indexes. These 2 indicators reflected the important index of respiratory muscle strength, which also implied that aerobic exercise in water effectively exercised the respiratory muscles, enhanced muscle strength and improved pulmonary ventilation function. However, no significant difference in the lung volume $\mathrm{VC}$ index observed between the three groups. The effects of lung volume are associated with the changes in the physiological structure of lung tissue caused by different diseases, and also factors such as body weight and body shape (55). After 16 weeks of smoke exposure and 9 weeks of exercise intervention, the body shape of the rats in different groups changed significantly. The body weight of rats in the CEG was decreased compared with that of the CMG rats, which is likely to affect certain lung volume indexes, such as VC.

In the present study, the mechanism of exercise-dependent improvement of the lung function in rats with COPD was not fully investigated. Results of the histological analyses indicated that there were no specific differences in the structures of the lung tissues between the CEG and CMG. Both groups exhibited the pathological characteristics of COPD, which suggested that the 9-week exercise intervention did not significantly reverse the pathological changes of lung tissue in COPD rats. It should be noted that the levels of inflammation in these sections were not analyzed in the present study. Although a previous study has confirmed that exercise does regulate inflammation in COPD airways and lung tissues (56), the markers of inflammation were not investigated and therefore it is not able to be concluded. In addition, although some studies have demonstrated that aerobic exercise reversed the airway remodeling in asthmatic mice $(57,58)$, the results of the present study suggested that the benefits of exercise on COPD were more significant in terms of respiratory muscle strength, exercise capacity and exercise-induced dyspnea, which is consistent with the conclusions of other previous studies (59-61).

Effects of exercise on the diaphragm of rats with COPD. A marked difference in the diaphragm function of the different groups was observed. The contractility of the diaphragm tissues in vitro was measured as a proxy for the muscle function (62), and the corresponding results indicated that the COPD rats exhibited a decline in diaphragm muscle strength. For patients with COPD, the respiratory muscles are exposed to an inhalation load for an extended period of time, and the diaphragm has to be in an active state to ensure survival, so it is less affected compared with the lower limb muscles. However, with the advances in COPD diaphragm research, the impairment of diaphragm function in these patients has been confirmed, and the associated pathological process has been gradually clarified (63). Due to a change in thoracic geometry, the diaphragm can be placed at an adverse contraction length. Concomitantly, the increasing ventilation load, exacerbations, nutritional abnormalities and aging would make the diaphragm undergo a compensatory period by functioning faster (12), which was also the final result observed in many diaphragms in the compensatory period $(64,65)$. Histological analysis of the model rats demonstrated a morphology similar to muscle atrophy, which was consistent with previous clinical studies $(66,67)$. Changes in muscle structure affected the normal function of the muscle. The comparison of diaphragm function and structure between the CEG and the CMG indicated that exercise significantly improved the diaphragm function, which was also consistent with previous studies $(68,69)$. Although other studies $(70,71)$ have indicated that physical exercise or respiratory re-education increased the strength of respiratory muscles, the effect of specific muscle training has been widely debated (72). In addition, the effectiveness of exercise training observed in the present study does not indicate that all types of exercise have beneficial effects on the diaphragms of patients with COPD. The ventilation load caused by conventional exercise intensity is insufficient to induce training adaptation (73). To decrease dyspnea and improve exercise ability, a specific ventilation 
load should be imposed on the respiratory muscles to improve the respiratory muscle function in COPD. Compared with land-based exercise, aquatic aerobic exercise has better suitability and acceptability for moderate to severe COPD $(22,74)$. Simultaneously, when exercising in water, the effects of water pressure and other factors ensure that the respiratory muscles and thorax of patients with COPD undergo stronger load stimulation, and these factors promote training adaption. In combination with the results concerning the effects of exercise on pulmonary function, these data suggest that exercise may serve an essential role in improving diaphragm function.

Biomarkers for improving diaphragmatic function by exercise. Multivariate statistical analysis ensured the validity of biomarker screening. Firstly, the PCA results demonstrated that, following dimensionality reduction, the principal components of the three groups of samples were quite different compared with when they were analyzed in pairs. Secondly, the OPLS-DA scatter plot results indicated that the samples in the different groups were significantly different, while the permutation test results excluded the possibility of false-positive data. The biomarkers screened from the established model had relatively high reliability. Although there was an outlier in the PCA and OPLS-DA data, the OPLS-DA model had good validity, and the physiological indexes (pulmonary function and diaphragm contractility) and histological data of this rat were not abnormal. Therefore, this sample was not eliminated in the subsequent analysis.

The improvement of diaphragm function by exercise was associated with the exercise-dependent promotion of the expression of various metabolites. The volcano maps indicated that the majority of the significantly different metabolites in the $\mathrm{CMG}$ were downregulated compared with the $\mathrm{CG}$, while the majority of the metabolites with significant differences were upregulated following the exercise intervention. Concomitantly, the decrease in diaphragm function in the COPD rats was likely to be associated with the downregulation of certain metabolites in the diaphragm. Following exercise training, the improvement of diaphragm function in the CEG rats was identified to be associated with the upregulation of a large number of metabolites in the diaphragm. Differential metabolites involved in both comparisons may be biomarkers associated with the exercise-dependent enhancement of diaphragm function. A total of 8 metabolites were identified: Threonine; serine; nicotinamide; lactic acid; citraconic acid; 3-cyanoalanine; dioctyl phthalate; and 2-hydroxypyridine.

Threonine is an essential amino acid for the human body. It is an important nutrient fortifier, which decreases fatigue and promotes growth and development. Muscle growth is known to be regulated by signal transduction pathways, which sense and compute local and systemic signals and regulate various cellular functions. Threonine, which is phosphorylated by phosphokinase, activates the mTOR signaling pathway, regulates the function of insulin-like growth factor-1/mechano growth factor/insulin and/or mechanical signals, amino acids and muscles, and correspondingly regulates protein synthesis to promote muscle growth (75). It has been suggested that exercise improved the level of threonine in vivo (76). In the present study, the increase in threonine levels in the diaphragms of the CEG rats and the decrease in threonine levels in the diaphragms of the $\mathrm{CMG}$ rats suggested that the improvement of the function of the diaphragm by exercise may be associated with the regulation of threonine levels.

Serine also serves a vital role in the human body. Serine is involved in the formation of cell membranes and the synthesis of myoprotein. It has been demonstrated that the carrier proteins serine incorporator 1-5 incorporates a polar amino acid serine into the membrane and promotes the synthesis of 2 serine-derived lipids, namely phosphatidylserine and sphingolipid (77). Pantaleo et al (78) suggested that the phosphorylation of serine residues is involved in the construction of cell membranes, based on the study of the erythrocyte membrane. A previous study has demonstrated that serine participates in the regulation of the mTOR pathway on skeletal muscle protein synthesis: Phosphorylation of serine residues on eukaryotic translation initiation factor $4 \mathrm{G}$ promotes muscle protein synthesis, and this process is regulated by the mTOR pathway (79). Exercise increases the levels of serine phosphorylation in the body, while supplementation of serine enhances exercise ability (80). Considering the results of the present study, the decline in respiratory muscle function in the COPD rats may be associated with the decrease in serine expression, and the increase in serine levels following exercise is also a potential mechanism for improving respiratory muscle function.

Nicotinamide is the amide form, and the primary form, of nicotinic acid. It is also the precursor of human synthetic coenzyme I dihydrouracil dehydrogenase (NAD+) and coenzyme II nicotinamide-adenine dinucleotide phosphate (NADP), which are key molecules widely present in cellular signaling pathways regulating cell metabolism and homeostasis. The presence of nicotinic acid is significant in regulating the level of oxidative stress in vivo. It inhibits phosphatidylserine externalization and late DNA damage in a unique way during oxidative stress (81). It is thought that nicotinamide-based protein secretion regulation removes reactive oxygen species and protects against oxidation. In addition, nicotinamide also regulates cell inflammation and inhibits inflammatory mediators $(82,83)$ such as interleukin (IL)-1 $\beta$, IL-6, IL-8, transforming growth factor $\beta-2$ and macrophage chemotactic protein-1 in liver cells. Nicotinamide also inhibits the production of tumor necrosis factor (83). Therefore, nicotinamide was demonstrated to participate in cellular metabolism processes and metabolic diseases, and it serves an important role in maintaining normal cell activities (84). Both intra- and extrapulmonary injuries in COPD are considered to be associated with oxidative stress and systemic inflammation. Whether this exercise-mediated elevation affects oxidative stress and inflammation through nicotinic acid requires further investigation.

Lactic acid is the intermediate product of carbohydrate metabolism in the anaerobic state and has been considered to be closely associated with exercise fatigue (85). Following $\geq 1$ intensive training sessions, a large amount of lactic acid is produced, and $\mathrm{H}^{+}$, produced by lactic acid dissociation, will decrease the environmental $\mathrm{pH}$ value, thereby inhibiting the excitability of muscle fibers and decreasing muscle contraction ability. However, follow-up studies have disputed the causal association between lactic acid-acidosis and muscle fatigue, and additional associated data demonstrated that lactic acid 
was a key component of local and global metabolism (86). It was identified that lactic acid elicits an anti-fatigue effect, and can be used as a 'mobile fuel' for other tissues and muscle fibers to maintain the blood sugar homeostasis (87). Lactic acid also maintains ATP production for cellular metabolic demands by stabilizing the redox potential and decreasing the difference in the $\mathrm{H}^{+}$concentration gradient inside and outside active muscle cells, decreasing $\mathrm{K}^{+}$release (88). In addition, lactic acid was suggested to have a certain antioxidant effect (89) and was associated with tissue damage repair (90). In the present study, the results indicated that the level of lactic acid in the diaphragm of the model rats decreased compared with the control rats, while the expression of lactic acid in the diaphragm of the exercise rats increased, which may involve a variety of roles for lactic acid. Future studies should be performed to elucidate these roles.

3 -cyanoalanine belongs to the class of organic compounds known as the 1-alpha-amino acids (91). Citraconic acid, also called 2-methylmaleate or methylmaleic acid, belongs to the class of organic compounds known as methyl-branched fatty acids (92). 2-hydroxypyridine is used in peptide synthesis (93). To the best of our knowledge, there have only been a few studies on these 3 substances in COPD and exercise-induced human metabolite changes, and further research is required. Dioctyl phthalate does not serve a role in the metabolism of mammals. Although this compound was qualitatively identified in the present study, the specific level of dioctyl phthalate and the reason for its appearance require further examination.

Biomarker pathway analysis of improving diaphragm function through exercise. The mechanism by which exercise improves diaphragm function may involve multiple metabolites and associated metabolic pathways. Pathway analysis of differential metabolites is useful in analyzing the specific regulation mechanism of exercise. By studying the pathways of different metabolites between different groups, the present study identified that the pathways involved in the exercise-dependent improvement of diaphragm function are most likely the nicotinate and nicotinamide metabolism and arginine and proline metabolism pathways. Notably, combined with previously published data, the glycine-serine-threonine metabolism and fatty acid biosynthesis and metabolism pathways may also be associated with the exercise-dependent enhancement of the diaphragm function. The nicotinate and nicotinamide pathways are potentially part of the mechanism by which exercise enhances diaphragm function. Nicotinate is oxidized by tryptophan and converted to nicotinamide in the small intestinal mucosa, which eventually binds to proteins to form NAD+ and NADP. A previous study demonstrated that moderate exercise accelerates nicotinic acid metabolism in vivo (94). The effects of exercise on the expression of NAD+ and NADP in vivo has been an ongoing topic of investigation (95). The results of the present study are also consistent with these studies: The training effect of exercise on the diaphragm may be associated with the local changes in the nicotinamide metabolic pathway.

The arginine and proline metabolic pathway serves a crucial role in the formation of cytoplasm and nucleic acid proteins, and in controlling protein renewal (96). Supplementary arginine increases the production of nitric oxide, and then induces the expression of utrophin and the activation of muscle satellite cells, thereby improving the pathological process of muscular dystrophy (97). Proline is not only the result of arginine metabolism but also the raw material for the synthesis of arginine (98). This process depends on the ornithine cycle, which renders the synthesis and metabolism of arginine recyclable. The pulmonary matrix is degraded in patients with COPD, and matrix metalloproteinases further destroy collagen fibers and degrade them into small fragments of proline and other amino acids. Hypoxic damage in patients with COPD is likely to be accompanied by the presence of methylated arginine products, which means that arginine may represent a biomarker of an acute attack of COPD (99). These methylated arginine products lead to airway obstruction through the decomposition of arginine (100). The pathways may also involve multiple extrapulmonary injuries $(101,102)$. For example, associated amino acids may contribute to the imbalance of protein synthesis and degradation in COPD skeletal muscle dysfunction and muscle atrophy (103). Early studies indicated that exercise affects the metabolism of arginine and proline, although in a manner that is dependent on exercise patterns and intensity $(94,95)$. Therefore, the effect of exercise on the metabolic pathway of arginine and proline may be one of the mechanisms through which exercise affects the function of the diaphragm muscle.

In the present study, it was identified that threonine and serine may contribute to exercise-dependent improvement of diaphragm function. The interaction between glycine, serine and threonine metabolism is close: Glycine and serine can be transformed into each other under the action of hydroxylmethyltransferase (104), while threonine can be decomposed into serine or glycine under the action of specific enzymes, such as hydroxymethyl transferase and threonine deaminase. The metabolism of these amino acids requires further study based on their vital biological functions.

Finally, lipid-associated processes, such as fatty acid synthesis and metabolism, were also identified in the comparison of the differential metabolite-associated pathways, although these factors were not significantly involved. With the in-depth studies on adipose tissue, in particular the identification of leptin (105), adiponectin (106), resistin (107) and chemokines (108), the multiple roles of adipose tissue in chronic diseases are gradually being revealed. Adipose tissue may serve a regulatory role in the body through multiple pathways (109). At present, exercise training has demonstrated a unique stimulating effect on the adipose tissue: Moderate exercise accelerates lipid metabolism $(110,111)$. Simultaneously, as the basic component of lipids, fatty acids are considered to be associated with COPD inflammation $(112,113)$, which suggests that changes in fatty acids are likely to be a potential factor affecting COPD disease progression. Adding a fatty acid supplement to the treatment regimen of patients with COPD on the basis of exercise training can improve the regulation of the immune response of the body, and the change in immune function can further affect the inflammatory response of the disease, thereby achieving effective exercise rehabilitation (114). According to the results of the present study, exercise may also affect the role of adipose tissue in the human body, producing therapeutic effects.

In the present study, CSE was used in the process of establishing animal models of COPD, which has been applied in numerous studies. However, the factors leading to COPD 
formation are complex: Multiple etiologies are considered to be associated with the occurrence of COPD, such as cigarette smoke, air pollution, metabolic derangements, genetics and aging (1,115). Unfortunately, the present study only simulated a COPD animal model using cigarette smoke, which is one of the study limitations. Pulmonary function tests and lung histology were used to identify COPD models. Following verification of the model, the remaining rats underwent an exercise intervention or were allowed to move freely. A 9-week intervention indicated the effectiveness of regular exercise and caused changes in multiple metabolites. In the present study, certain physiological values were measured, such as diaphragm function and pulmonary function tests, to measure diaphragm function directly or indirectly, respectively. Nevertheless, these indicators are not sufficient, and more assessments of the function of the target muscles and physiological studies should be performed, which is one of the limitations of the present study, as the closer the relationship between biological alternations and pathophysiological phenomena, the more meaningful the results of biological analysis will be. Future studies should focus on the quantitative changes of differential metabolites and their metabolic pathways. Furthermore, the present study group will conduct knockout/overexpression studies of the metabolic pathways of the metabolites identified in the present study, to observe whether the effect of exercise on the improvement of diaphragm function is affected. Whether the biomarkers identified in the present study are also relevant in patients with COPD remains to be established, as the present study focused on a COPD animal model.

In conclusion, physiological studies and biological analyses were used in the present study. Following confirmation of the improvement in diaphragm function, metabolomics research methods were applied to explore the potential molecular biology mechanism of exercise training to improve diaphragm function in COPD. A total of 4 metabolites (threonine, serine, nicotinamide and lactic acid) were considered as potential biomarkers to enhance the diaphragm function in COPD rats. Concomitantly, through the analysis of the pathways of different metabolites, 2 pathways, the nicotinic acid and nicotinamide metabolism and arginine and proline metabolism pathways, were identified to be the most likely metabolic pathways involved in the exercise-based improvement of diaphragm function. The present study provides a reference for exploring the mechanism of pulmonary rehabilitation through screening biomarkers and associated pathways by metabolomics, but further studies are required.

\section{Acknowledgements}

Not applicable.

\section{Funding}

The present study was supported by the National Natural Science Foundation of China (grant no. 81902307).

\section{Availability of data and materials}

The data used and/or analyzed during the present study are available from the corresponding author on reasonable request.

\section{Authors' contributions}

JL, WW and XL made substantial contributions to the conception and design of the study. YL, NL, PL, ZW, TW, ZY and YY acquired, analyzed and interpreted the data. JL, JS, HC, LX and HD drafted the article and revised it critically for important intellectual content. All authors read and approved the final manuscript. All authors agree to be held accountable for all aspects of the work in ensuring that questions related to the accuracy or integrity of the work are appropriately investigated and resolved.

\section{Ethics approval and consent to participate}

The experimental protocol was approved by the Institutional Animal Care and Use Committee of Shanghai University of Sport (approval no. 2018026), and was conducted following the Animal Research Guidelines of the Shanghai University of Sport.

\section{Patient consent for publication}

Not applicable.

\section{Competing interests}

The authors declare that they have no competing interests.

\section{References}

1. Horner A, Soriano JB, Puhan MA, Studnicka M, Kaiser B, Vanfleteren LEGW, Gnatiuc L, Burney P, Miravitlles M, García-Rio F, et al: Altitude and COPD prevalence: Analysis of the PREPOCOL-PLATINO-BOLD-EPI-SCAN study. Respir Res 18: 162, 2017.

2. Mesquita R, Donária L, Genz IC, Pitta F and Probst VS: Respiratory muscle strength during and after hospitalization for COPD exacerbation. Respir Care 58: 2142-2149, 2013.

3. Hodgev VA and Kostianev SS: Maximal inspiratory pressure predicts mortality in patients with chronic obstructive pulmonary disease in a five-year follow-up. Folia Med 48: 36-41, 2006.

4. Newell SZ, McKenzie DK and Gandevia SC: Inspiratory and skeletal muscle strength and endurance and diaphragmatic activation in patients with chronic airflow limitation. Thorax 44: 903-912, 1989.

5. Fabbri LM and Rabe KF: From COPD to chronic systemic inflammatory syndrome? Lancet 370: 797-799, 2007.

6. Kirkham PA and Barnes PJ: Oxidative stress in COPD. Chest 144: 266-273, 2013

7. Rochester DF: The diaphragm in COPD. Better than expected, but not good enough. New Engl J Med 325: 961-962, 1991.

8. Scott A, Wang X, Road JD and Reid WD: Increased injury and intramuscular collagen of the diaphragm in COPD: Autopsy observations. Eur Respir J 27: 51-59, 2006.

9. Doucet M, Debigare R, Joanisse DR, Côté C,Leblanc P, Grégoire J, Deslauriers J, Vaillancourt R and Maltais F: Adaptation of the diaphragm and the vastus lateralis in mild-to-moderate COPD. Eur Respir J 24: 971-979, 2004.

10. Haegens A, Schols AM, Gorissen SH, van Essen AL, Snepvangers F, Gray DA, Shoelson SE and Langen RC: NF- $\kappa B$ activation and polyubiquitin conjugation are required for pulmonary inflammation-induced diaphragm atrophy. Am J Physiol Lung Cell Mol Physiol 302: L103-L110, 2012.

11. Wijnhoven HJ, Heunks LM, Geraedts MC, Hafmans T, Viña JR and Dekhuijzen PN: Oxidative and nitrosative stress in the diaphragm of patients with COPD. Int J Chron Obstruct Pulmon Dis 1: 173-179, 2006.

12. Barreiro E and Gea J: Respiratory and limb muscle dysfunction in COPD. COPD 12: 413-426, 2015. 
13. Nici L, Donner C, Wouters E, Zuwallack R, Ambrosino N, Bourbeau J, Carone M, Celli B, Engelen M, Fahy B, et al: American thoracic society/European respiratory society statement on pulmonary rehabilitation. Am J Respir Crit Care Med 173: 1390-1413, 2006.

14. Ricci C, Terzoni S, Gaeta M, Sorgente A, Destrebecq A and Gigliotti F: Physical training and noninvasive ventilation in COPD patients: A meta-analysis. Respir Care 59: 709-717, 2014.

15. Polkey MI, Kyroussis D, Hamnegard CH, Mills GH, Green M and Moxham J: Diaphragm strength in chronic obstructive pulmonary disease. Am J Respir Crit Care Med 154: 1310-1317, 1996.

16. Koulmann $\mathrm{N}$ and Bigard AX: Interaction between signalling pathways involved in skeletal muscle responses to endurance exercise. Pflugers Arch 452: 125-139, 2006.

17. Rowell LB, Sheriff DD, Wyss CR and Scher AM: The nature of the exercise stimulus. Acta Physiol Scand Suppl 556: 7-14, 1986.

18. Casado-Vela J, Cebrián A, Gómez del Pulgar MT and Lacal JC: Approaches for the study of cancer: Towards the integration of genomics, proteomics and metabolomics. Clin Transl Oncol 13: 617-628, 2011.

19. Cox J and Mann M: Is proteomics the new genomics? Cell 130 395-398, 2007.

20. Lindon JC, Holmes E and Nicholson JK: Metabonomics techniques and applications to pharmaceutical research \& development. Pharm Res 23: 1075-1088, 2006.

21. Lindon JC,Holmes E, Bollard ME, Stanley EG and Nicholson JK: Metabonomics technologies and their applications in physiological monitoring, drug safety assessment and disease diagnosis. Biomarkers 9: 1-31, 2004.

22. Wadell K: Water-based exercise is more effective than land-based exercise for people with COPD and physical comorbidities. J Physiother 60: 57, 2014.

23. Wu W, Liu X, Liu J, Li P and Wang Z: Effectiveness of water-based Liuzijue exercise on respiratory muscle strength and peripheral skeletal muscle function in patients with COPD. Int J Chron Obstruct Pulmon Dis 13: 1713-1726, 2018

24. Carlos SP, Dias AS, Forgiarini Júnior LA, Patricio PD, Graciano T, Nesi RT, Valença S, Chiappa AM, Cipriano G Jr, Souza CT and Chiappa GR: Oxidative damage induced by cigarette smoke exposure in mice: Impact on lung tissue and diaphragm muscle J Bras Pneumol 40: 411-420, 2014 (In English, Portuguese)

25. Vieira Ramos G, Choqueta de Toledo-Arruda A, Maria Pinheiro-Dardis C, Liyoko Suehiro C, Luiz de Russo T, Vieira RP, Arruda Martins M, Salvini TF and Durigan JLQ: Exercise prevents diaphragm wasting induced by cigarette smoke through modulation of antioxidant genes and metalloproteinases. Biomed Res Int 2018: 5909053, 2018.

26. Bowen TS, Aakerøy L, Eisenkolb S, Kunth P, Bakkerud F, Wohlwend M, Ormbostad AM, Fischer T, Wisloff U, Schuler G, et al: Exercise training reverses extrapulmonary impairments in smoke-exposed mice. Med Sci Sports Exerc 49: 879-887, 2017.

27. Barreiro E, del Puerto-Nevado L, Puig-Vilanova E, Pérez-Rial S, Sánchez F, Martínez-Galán L, Rivera S, Gea J, González-Mangado N and Peces-Barba G: Cigarette smoke-induced oxidative stress in skeletal muscles of mice. Respir Physiol Neurobiol 182: 9-17, 2012.

28. Krüger K, Dischereit G, Seimetz M, Wilhelm J, Weissmann N and Mooren FC: Time course of cigarette smoke-induced changes of systemic inflammation and muscle structure. Am J Physiol Lung Cell Mol Physiol 309: L119-L128, 2015.

29. Wüst RCI and Degens H: Factors contributing to muscle wasting and dysfunction in COPD patients. Int J Chron Obstruct Pulmon Dis 2: 289-300, 2007

30. Nie YC, Wu H, Li PB, Luo YL, Zhang CC, Shen JG and $\mathrm{Su}$ WW: Characteristic comparison of three rat models induced by cigarette smoke or combined with LPS: To establish a suitable model for study of airway mucus hypersecretion in chronic obstructive pulmonary disease. Pulm Pharmacol Ther 25 : 349-356, 2012

31. Caron MA, Morissette MC, Thériault ME, Nikota JK, Stämpfli MR and Debigaré R: Alterations in skeletal muscle cell homeostasis in a mouse model of cigarette smoke exposure. PLoS One 8: e66433, 2013.

32. Totou NL, Moura SS, Coelho DB, Oliveira EC, Becker LK and Lima WG: Swimming exercise demonstrates advantages over running exercise in reducing proteinuria and glomerulosclerosis in spontaneously hypertensive rats. Physiol Int 105: 76-85, 2018.
33. Barbosa Neto O, Abate DT, Marocolo Júnior M, Mota GR, Orsatti FL, Rossi e Silva RC, Reis MA and da Silva VJ: Exercise training improves cardiovascular autonomic activity and attenuates renal damage in spontaneously hypertensive rats. J Sports Sci Med 12: 52-59, 2013.

34. Egawa T, Tsuda S, Goto A, Ohno Y, Yokoyama S, Goto K and Hayashi T: Potential involvement of dietary advanced glycation end products in impairment of skeletal muscle growth and muscle contractile function in mice. Br J Nutr 117: 21-29, 2017.

35. Yao S, Zhang J, Chen H, Sheng Y, Zhang X, Liu Z and Zhang C Diagnostic value of immunohistochemical staining of GP73, GPC3, DCP, CD34, CD31, and reticulin staining in hepatocellular carcinoma. J Histochem Cytochem 61: 639-648, 2013.

36. Kind T, Wohlgemuth G, Lee DY, Lu Y, Palazoglu M, Shahbaz S and Fiehn O: FiehnLib: Mass spectral and retention index libraries for metabolomics based on quadrupole and time-of-flight gas chromatography/mass spectrometry. Anal Chem 81: 10038-10048, 2009.

37. Dunn WB, Broadhurst D, Begley P,Zelena E, Francis-McIntyre S, Anderson N, Brown M, Knowles JD, Halsall A, Haselden JN, et al: Procedures for large-scale metabolic profiling of serum and plasma using gas chromatography and liquid chromatography coupled to mass spectrometry. Nat Protoc 6: 1060-1083, 2011.

38. Alfakih A, Khandani A and Wolkowicz H: Solving Euclidean distance matrix completion problems via semidefinite programming. Comput Optim Appl 12: 13-30, 1999.

39. Kanehisa $M$ and Goto S: KEGG: Kyoto encyclopedia of genes and genomes. Nucleic Acids Res 28: 27-30, 2000.

40. Kanehisa M, Sato Y, Kawashima M, Furumichi M and Tanabe M: KEGG as a reference resource for gene and protein annotation. Nucleic Acids Res 44 (D1): D457-D462, 2016.

41. Toledo AC, Magalhaes RM, Hizume DC, Vieira RP, Biselli PJ, Moriya HT, Mauad T, Lopes FD and Martins MA: Aerobic exercise attenuates pulmonary injury induced by exposure to cigarette smoke. Eur Respir J 39: 254-264, 2012.

42. Ma WL, Cai PC, Xiong XZ and Ye H: Exercise training attenuated chronic cigarette smoking-induced up-regulation of FIZZ1/RELM $\alpha$ in lung of rats. J Huazhong Univ Sci Technolog Med Sci 33: 22-26, 2013.

43. Nishii Y, Kawata S, Fujita N, Tomoda K and Imagita H: Moderate exercise attenuated airway resistance and inflammation induced by cigarette smoke solution and endotoxin in rats. Sport Sci Health 12: 91-97, 2016.

44. Eklund BM, Nilsson S, Hedman L and Lindberg I: Why do smokers diagnosed with COPD not quit smoking?-a qualitative study. Tob Induc Dis 10: 17, 2012.

45. Taghizadeh N, Vonk JM and Boezen HM: Lifetime smoking history and cause-specific mortality in a cohort study with 43 years of follow-up. PLoS One 11: e0153310, 2016.

46. Klaude M, Gedik CM and Collins AR: DNA damage and repair after low doses of UV-C radiation; comparable rates of repair in rodent and human cells. Int J Radiat Biol 67: 501-508, 1995.

47. Rees DC, Wood RW and Laties VG: Stimulus control and the development of behavioral tolerance to daily injections of d-amphetamine in the rat. J Pharmacol Exp Ther 240: 65-73, 1987.

48. Siegel S and Sdao-Jarvie K: Attenuation of ethanol tolerance by a novel stimulus. Psychopharmacology 88: 258-261, 1986.

49. Swanny A, Morton RF and Lee LY: Acute effect of cigarette smoke on breathing is attenuated by chronic smoking in rats. J Appl Physiol (1985) 74: 333-338, 1993.

50. Thames HD Jr, Withers HR and Peters LJ: Tissue repair capacity and repair kinetics deduced from multifractionated or continuous irradiation regimens with incomplete repair. Br J Cancer Suppl 6: 263-269, 1984

51. Rinaldi M,Maes K, De Vleeschauwer S, Thomas D, Verbeken EK, Decramer M, Janssens W and Gayan-Ramirez GN: Long-term nose-only cigarette smoke exposure induces emphysema and mild skeletal muscle dysfunction in mice. Dis Model Mech 5: 333-341, 2012.

52. Berry CE and Wise RA: Interpretation of pulmonary function test: Issues and controversies. Clin Rev Allergy Immunol 37: 173-180, 2009.

53. Cukic V, Lovre V and Ustamujic A: The changes of pulmonary function in COPD during four-year period. Mater Sociomed 25 88-92, 2013.

54. Wang J, Zhou XM, Yang X, Zhao ST, Ma QL and Wang CZ: A three years longitudinal follow-up study of pulmonary function changes in patients with chronic obstructive pulmonary disease. Chin J Intern Med 55: 302-306, 2016 (In Chinese). 
55. Talaminos Barroso A, Márquez Martin E, Roa Romero LM and Ortega Ruiz F: Factors affecting lung function: A review of the literature. Arch Bronconeumol 54: 327-332, 2018 (In English, Spanish).

56. Davidson WJ, Verity WS, Traves SL, Leigh R, Ford GT and Eves ND: Effect of incremental exercise on airway and systemic inflammation in patients with COPD. J Appl Physiol (1985) 112: 2049-2056, 2012.

57. Silva RA, Almeida FM, Olivo CR, Saraiva-Romanholo BM, Martins MA and Carvalho CR: Airway remodeling is reversed by aerobic training in a murine model of chronic asthma. Scand J Med Sci Sports 25: e258-e266, 2015.

58. Vieira RP, Claudino RC, Duarte AC, Santos AB, Perini A, Faria Neto HC, Mauad T, Martins MA, Dolhnikoff M and Carvalho CR: Aerobic exercise decreases chronic allergic lung inflammation and airway remodeling in mice. Am J Respir Crit Care Med 176: 871-877, 2007.

59. Lan CC, Chu WH, Yang MC, Lee $\mathrm{CH}$, Wu YK and Wu CP Benefits of pulmonary rehabilitation in patients with COPD and normal exercise capacity. Respir Care 58: 1482-1488, 2013.

60. Ambrosino N, Foglio K, Balzano G, Paggiaro PL, Lessi P and Kesten S; Tiotropium Multicentric Italian Study Group: Tiotropium and exercise training in COPD patients: Effects on dyspnea and exercise tolerance. Int J Chron Obstruct Pulmon Dis 3: 771-780, 2008.

61. Leelarungrayub J, Pinkaew D, Puntumetakul R and Klaphajone J: Effects of a simple prototype respiratory muscle trainer on respiratory muscle strength, quality of life and dyspnea, and oxidative stress in COPD patients: A preliminary study. Int $\mathrm{J}$ Chron Obstruct Pulmon Dis 12: 1415-1425, 2017.

62. Armbruster C, Dassow C, Gamerdinger K, Guttmann J, Schneider M and Schumann S: In vitro muscle contraction force measurements on isolated and entire rat diaphragms. Critical Care 14: P204, 2010.

63. Gea J, Agusti A and Roca J: Pathophysiology of muscle dysfunction in COPD. J Appl Physiol (1985) 114: 1222-1234, 2013.

64. Levine S, Bashir MH, Clanton TL, Powers SK and Singhal S: COPD elicits remodeling of the diaphragm and vastus lateralis muscles in humans. J Appl Physiol (1985) 114: 1235-1245, 2013.

65. Gayan-Ramirez G and Decramer M: Mechanisms of striated muscle dysfunction during acute exacerbations of COPD. J App Physiol (1985) 114: 1291-1299, 2013.

66. Levine S, Kaiser L, Leferovich J and Tikunov B: Cellular adaptations in the diaphragm in chronic obstructive pulmonary disease. N Engl J Med 337: 1799-1806, 1997.

67. Marin-Corral J, Minguella J, Ramirez-Sarmiento AL, Hussain SN, Gea J and Barreiro E: Oxidised proteins and superoxide anion production in the diaphragm of severe COPD patients. Eur Respir J 33: 1309-1319, 2009.

68. Spruit MA, Gosselink R, Troosters T, De Paepe K and Decramer M: Resistance versus endurance training in patients with COPD and peripheral muscle weakness. Eur Respir J 19: 1072-1078, 2002.

69. Franssen FM, Broekhuizen R, Janssen PP, Wouters EF and Schols AM: Effects of whole-body exercise training on body composition and functional capacity in normal-weight patients with COPD. Chest 125: 2021-2028, 2004

70. Cortopassi F, Castro AA, Porto EF, Colucci M, Fonseca G, Torre-Bouscoulet L, Iamonti V and Jardim JR: Comprehensive exercise training improves ventilatory muscle function and reduces dyspnea perception in patients with COPD. Monaldi Arch Chest Dis 71: 106-112, 2009.

71. Wada JT, Borges-Santos E, Porras DC, Paisani DM, Cukier A, Lunardi AC and Carvalho CR: Effects of aerobic training combined with respiratory muscle stretching on the functional exercise capacity and thoracoabdominal kinematics in patients with COPD: A randomized and controlled trial. Int J Chron Obstruct Pulmon Dis 11: 2691-2700, 2016.

72. Ries AL, Bauldoff GS, Carlin BW, Casaburi R, Emery CF, Mahler DA, Make B, Rochester CL, Zuwallack R and Herrerias C: Pulmonary rehabilitation: Joint ACCP/AACVPR evidence-based clinical practice guidelines. Chest 131 (5 Suppl): 4S-42S, 2007.

73. Wanke T, Formanek D, Lahrmann H, Brath H, Wild M, Wagner C and Zwick H: Effects of combined inspiratory muscle and cycle ergometer training on exercise performance in patients with COPD. Eur Respir J 7: 2205-2211, 1994.

74. de Souto Araujo ZT, de Miranda Silva Nogueira PA, Cabral EE, de Paula Dos Santos L, da Silva IS and Ferreira GM: Effectiveness of low-intensity aquatic exercise on COPD: A randomized clinical trial. Respir Med 106: 1535-1543, 2012.
75. Wackerhage $\mathrm{H}$ and Ratkevicius A: Signal transduction pathways that regulate muscle growth. Essays Biochem 44: 99-108, 2008.

76. Chaouloff F, Kennett GA, Serrurrier B, Merino D and Curzon G: Amino acid analysis demonstrates that increased plasma free tryptophan causes the increase of brain tryptophan during exercise in the rat. J Neurochem 46: 1647-1650, 1986.

77. Inuzuka M, Hayakawa M and Ingi T: Serinc, an activity-regulated protein family, incorporates serine into membrane lipid synthesis. J Biol Chem 280: 35776-35783, 2005.

78. Pantaleo A, Ferru E, Carta F, Mannu F, Giribaldi G, Vono R, Lepedda AJ, Pippia P and Turrini F: Analysis of changes in tyrosine and serine phosphorylation of red cell membrane proteins induced by P. falciparum growth. Proteomics 10: 3469-3479, 2010.

79. Hu SI, Katz M, Chin S, Qi X, Cruz J, Ibebunjo C, Zhao S, Chen A and Glass DJ: MNK2 inhibits eIF4G activation through a pathway involving serine-arginine-rich protein kinase in skeletal muscle. Sci Signal 5: ra14, 2012.

80. Talanian JL, Tunstall RJ, Watt MJ, Duong M, Perry CG, Steinberg GR, Kemp BE, Heigenhauser GJ and Spriet LL: Adrenergic regulation of HSL serine phosphorylation and activity in human skeletal muscle during the onset of exercise. Am J Physiol Regul Integr Comp Physiol 291: R1094-R1099, 2006.

81. Li F, Chong ZZ and Maiese K: Cell life versus cell longevity: The mysteries surrounding the NAD+ precursor nicotinamide. Curr Med Chem 13: 883-895, 2006.

82. Ungerstedt JS, Blömback M and Söderström T: Nicotinamide is a potent inhibitor of proinflammatory cytokines. Clin Exp Immunol 131: 48-52, 2003.

83. Traister A, Breitman I, Bar-Lev E, Zvibel I, Harel A, Halpern Z and Oren R: Nicotinamide induces apoptosis and reduces collagen I and pro-inflammatory cytokines expression in rat hepatic stellate cells. Scand J Gastroenterol 40: 1226-1234, 2005.

84. Chlopicki S, Swies J, Mogielnicki A, Buczko W, Bartus M, Lomnicka M, Adamus J and Gebicki J: 1-Methylnicotinamide (MNA), a primary metabolite of nicotinamide, exerts anti-thrombotic activity mediated by a cyclooxygenase-2/prostacyclin pathway. Br J Pharmacol 152: 230-239, 2007.

85. Surenkok O, Kin-Isler A, Aytar A and Gültekin Z: Effect of trunk-muscle fatigue and lactic acid accumulation on balance in healthy subjects. J Sport Rehabil 17: 380-386, 2008.

86. Robergs RA, Ghiasvand F and Parker D: Biochemistry of exercise-induced metabolic acidosis. Am J Physiol Regul Integr Comp Physiol 287: R502-R516, 2004.

87. Gladden LB: Lactate metabolism: A new paradigm for the third millennium. J Physiol 558: 5-30, 2004.

88. Lewis SF and Haller RG: The pathophysiology of McArdle's disease: Clues to regulation in exercise and fatigue. J Appl Physiol (1985) 61: 391-401, 1986.

89. Hunt TK, Aslam R, Hussain Z and Beckert S: Lactate, with oxygen, incites angiogenesis. Adv Exp Med Biol 614: 73-80, 2008.

90. Groussard C, Morel I, Chevanne M, Monnier M, Cillard J and Delamarche A: Free radical scavenging and antioxidant effects of lactate ion: An in vitro study. J Appl Physiol (1985) 89: $169-175,2000$.

91. Thiele I, Swainston N, Fleming RM, Hoppe A, Sahoo S, Aurich MK, Haraldsdottir H, Mo ML, Rolfsson O, Stobbe MD, et al: A community-driven global reconstruction of human metabolism. Nat Biotechnol 31: 419-425, 2013.

92. Stoltz JF and Nicolas A: Study of amino groups of the human platelet membrane. Acta Haematol 60: 304-309, 1978.

93. Menon R, Tolbert D and Cefali E: The comparative bioavailability of an extended-release niacin and lovastatin fixed dose combination tablet versus extended-release niacin tablet, lovastatin tablet and a combination of extended-release niacin tablet and lovastatin tablet. Biopharm Drug Dispos 28: 297-306, 2007.

94. Shibata K, Matsumoto K, Fushiki T and Sugimoto E: Effects of exercise on the metabolism of NAD in rats. Biosci Biotech Bioch 58: 1763-1766, 1994.

95. White AT and Schenk S: NAD(+)/NADH and skeletal muscle mitochondrial adaptations to exercise. Am J Physiol Endocrinol Metab 303: E308-E321, 2012.

96. Wu G and Morris SM Jr: Arginine metabolism: Nitric oxide and beyond. Biochem J 336: 1-17, 1998.

97. Barton ER, Morris L, Kawana M, Bish LT and Toursel T: Systemic administration of L-arginine benefits mdx skeletal muscle function. Muscle nerve 32: 751-760, 2005. 
98. Wu G, Bazer FW, Datta S, Johnson GA, Li P, Satterfield MC and Spencer TE: Proline metabolism in the conceptus: Implications for fetal growth and development. Amino Acids 35: 691-702, 2008.

99. Ruzsics I, Nagy L, Keki S, Sarosi V, Illes B, Illes Z, Horvath I, Bogar L and Molnar T: L-arginine pathway in COPD patients with acute exacerbation: A new potential biomarker. COPD 13 139-145, 2016.

100. Dohm GL, Beecher GR, Warren RQ and Williams RT: Influence of exercise on free amino acid concentrations in rat tissues. J Appl Physiol Respir Environ Exerc Physiol 50: 41-44, 1981.

101. Parmaksız ET, Inal A, Salepci B, Comert S, Fidan A, Kiral N, Doğan $C$ and Caglayan B: Relationship of asymmetric dimethylarginine levels with disease severity and pulmonary hypertension in chronic obstructive pulmonary disease. Lung India 35: 199-203, 2018

102. van den Berg MP, Meurs H and Gosens R: Targeting arginase and nitric oxide metabolism in chronic airway diseases and their co-morbidities. Curr Opin Pharmacol 40: 126-133, 2018.

103. Hörster I, Weigt-Usinger K, Carmann C, Chobanyan-Jürgens K, Köhler C, Schara U, Kayacelebi AA, Beckmann B, Tsikas D and Lücke T: The L-arginine/NO pathway and homoarginine are altered in Duchenne muscular dystrophy and improved by glucocorticoids. Amino Acids 47: 1853-1863, 2015.

104. Wang W, Wu Z, Dai Z, Yang Y, Wang J and Wu G: Glycine metabolism in animals and humans: Implications for nutrition and health. Amino Acids 45: 463-477, 2013.

105. Bruno A, Chanez P, Chiappara G, Siena L, Giammanco S, Gjomarkaj M, Bonsignore G, Bousquet J and Vignola AM: Does leptin play a cytokine-like role within the airways of COPD patients? Eur Respir J 26: 398-405, 2005.

106. Bianco A, Mazzarella G, Turchiarelli V, Nigro E, Corbi G, Scudiero O, Sofia M and Daniele A: Adiponectin: An attractive marker for metabolic disorders in chronic obstructive pulmonary disease (COPD). Nutrients 5: 4115-4125, 2013.

107. Al Mutairi SS, Mojiminiyi OA, Shihab-Eldeen A, Al Rammah T and Abdella N: Putative roles of circulating resistin in patients with asthma, COPD and cigarette smokers. Dis Markers 31: 1-7, 2011.
108. Tomaki M, Sugiura H, Koarai A, Komaki Y, Akita T, Matsumoto T, Nakanishi A, Ogawa H, Hattori T and Ichinose M: Decreased expression of antioxidant enzymes and increased expression of chemokines in COPD lung. Pulm Pharmacol Ther 20: 596-605, 2007.

109. Tilg H and Moschen AR: Adipocytokines: Mediators linking adipose tissue, inflammation and immunity. Nat Rev Immunol 6: $772-783,2006$

110. Horowitz JF and Klein S: Lipid metabolism during endurance exercise. Am J Clin Nutr 72 (2 Suppl): 558S-563S, 2000

111. Gill JM, Frayn KN, Wootton SA, Miller GJ and Hardman AE: Effects of prior moderate exercise on exogenous and endogenous lipid metabolism and plasma factor VII activity. Clin Sci (Lond) 100: 517-527, 2001.

112. de Batlle J, Sauleda J, Balcells E, Gómez FP, Méndez M, Rodriguez E, Barreiro E, Ferrer JJ, Romieu I, Gea J, et al: Association between $\Omega 3$ and $\Omega 6$ fatty acid intakes and serum inflammatory markers in COPD. J Nutr Biochem 23: 817-821, 2012.

113. Warnakulasuriya SN, Ziaullah and Rupasinghe HP: Novel long chain fatty acid derivatives of quercetin-3-O-glucoside reduce cytotoxicity induced by cigarette smoke toxicants in human fetal lung fibroblasts. Eur J Pharmacol 781: 128-138, 2016.

114. Garrod R, Ansley P, Canavan J and Jewell A: Exercise and the inflammatory response in chronic obstructive pulmonary disease (COPD)-Does training confer anti-inflammatory properties in COPD? Med Hypotheses 68: 291-298, 2007.

115. Spurzem JR and Rennard SI: Pathogenesis of COPD. Semin Respir Crit Care Med 26: 142-153, 2005.

This work is licensed under a Creative Commons Attribution-NonCommercial-NoDerivatives 4.0 International (CC BY-NC-ND 4.0) License. 